\title{
Singular localization of sodium channel $\beta 4$ subunit in unmyelinated fibres and its role in the striatum
}

Haruko Miyazaki 1,2,3,4, Fumitaka Oyama ${ }^{2,5}$, Ritsuko Inoue ${ }^{6}$, Toshihiko Aosaki ${ }^{6}$, Takaya Abe ${ }^{7}$, Hiroshi Kiyonari ${ }^{7}$, Yoshihiro Kino 1,2,3,4, Masaru Kurosawa,2,3,4, Jun Shimizu' ${ }^{8}$, Ikuo Ogiwara9 ${ }^{9}$ Kazuhiro Yamakawa9, Yoshinori Koshimizu ${ }^{10}$, Fumino Fujiyama4,10,11, Takeshi Kaneko ${ }^{10}$, Hideaki Shimizu ${ }^{12}$, Katsuhiro Nagatomo ${ }^{13}$, Katsuya Yamada ${ }^{13}$, Tomomi Shimogori ${ }^{3}$, Nobutaka Hattori ${ }^{14}$, Masami Miura ${ }^{6}$ \& Nobuyuki Nukina ${ }^{1,2,3,4}$

Voltage-gated $\mathrm{Na}^{+}$channel $\beta$-subunits are multifunctional molecules that modulate $\mathrm{Na}^{+}$ channel activity and regulate cell adhesion, migration and neurite outgrowth. $\beta$-subunits including $\beta 4$ are known to be highly concentrated in the nodes of Ranvier and axon initial segments in myelinated axons. Here we show diffuse $\beta 4$ localization in striatal projection fibres using transgenic mice that express fluorescent protein in those fibres. These axons are unmyelinated, forming large, inhibitory fibre bundles. Furthermore, we report $\beta 4$ dimer expression in the mouse brain, with high levels of $\beta 4$ dimers in the striatal projection fascicles, suggesting a specific role of $\beta 4$ in those fibres. Scn $4 b$-deficient mice show a resurgent $\mathrm{Na}^{+}$current reduction, decreased repetitive firing frequency in medium spiny neurons and increased failure rates of inhibitory postsynaptic currents evoked with repetitive stimulation, indicating an in vivo channel regulatory role of $\beta 4$ in the striatum.

\footnotetext{
${ }^{1}$ Department of Neuroscience for Neurodegenerative Disorders, Juntendo University Graduate School of Medicine, 2-1-1 Hongo, Bunkyo-ku, Tokyo 113-8421, Japan. ${ }^{2}$ Laboratory for Structural Neuropathology, RIKEN Brain Science Institute, 2-1 Hirosawa, Wako-shi, Saitama 351-0198, Japan. ${ }^{3}$ Laboratory for Molecular Mechanisms of Thalamus Development, RIKEN Brain Science Institute, 2-1 Hirosawa, Wako-shi, Saitama 351-0198, Japan. ${ }^{4}$ CREST (Core Research for Evolutionary Science and Technology), JST, 7 Gobancho, Chiyoda-ku, Tokyo 102-0076, Japan. ${ }^{5}$ Department of Applied Chemistry, Kogakuin University, 2665-1 Nakano-cho, Hachioji, Tokyo 192-0015, Japan. ${ }^{6}$ Neurophysiology Research Group, Tokyo Metropolitan Institute of Gerontology, 35-2 Sakae-cho, Itabashi-ku, Tokyo 173-0015, Japan. ${ }^{7}$ Laboratory for Animal Resources and Genetic Engineering, RIKEN Center for Developmental Biology, 2-2-3 Minatojima Minami, Chuou-ku, Kobe 650-0047, Japan. ${ }^{8}$ Department of Neurology, University of Tokyo, 7-3-1 Hongo, Bunkyo-ku, Tokyo 113-8654, Japan. ${ }^{9}$ Laboratory for Neurogenetics, RIKEN Brain Science Institute, 2-1 Hirosawa, Wako-shi, Saitama 351-0198, Japan. ${ }^{10}$ Department of Morphological Brain Science, Graduate School of Medicine, Kyoto University, Kyoto 606-8501, Japan. ${ }^{11}$ Laboratory for Neural Circuitry, Graduate School of Brain Science, Doshisha University, 4-1-1 Kizugawadai, Kizugawa-shi, Kyoto 619-0225, Japan. ${ }^{12}$ RIKEN Center for Life Science Technology, 1-7-22 Suehiro-cho, Tsurumi-ku, Yokohama 230-0045, Japan. ${ }^{13}$ Department of Physiology, Hirosaki University School of Medicine, 5 Zaifu-cho, Hirosaki, Aomori 036-8562, Japan.

${ }^{14}$ Department of Neurology, Juntendo University Graduate School of Medicine, 2-1-1 Hongo, Bunkyo-ku, Tokyo 113-8421, Japan. Correspondence and requests for materials should be addressed to N.N. (email: nnukina@juntendo.ac.jp).
} 
$\mathrm{V}$ oltage-gated $\mathrm{Na}^{+}$channels (VGSCs) are a large, multimeric complex that consists of a pore-forming $\alpha$-subunit and one or more auxiliary $\beta$-subunits ${ }^{1}$. Four different VGSC $\beta$-subunits ( $\beta 1-\beta 4)$, encoded by genes $S c n 1 b-S c n 4 b$, are expressed in the nervous system ${ }^{1,2}$. VGSC $\beta$-subunits are multifunctional molecules that modulate $\mathrm{Na}^{+}$current kinetics and regulate channel cell surface expression and neurite outgrowth $^{3-5}$. On the basis of structural and amino-acid homologies, VGSC $\beta$-subunits belong to the immunoglobulin superfamily of cell adhesion molecules (IgCAMs) ${ }^{6}$. Thus, a growing hypothesis is that VGSC $\beta$-subunits play a crucial role in both modulating action potential firing and cell-adhesion-related activities $^{2}$.

$\beta 4$ is similar to the $\beta 2$ subunit (35\% identity) and contains an extracellular Ig-like domain ${ }^{7}$ that interacts with the $\alpha$-subunit through a cysteine residue. This interaction is required for $\beta 4$ recruitment at the nodes of Ranvier ${ }^{8}$. $\beta 4$ is associated with resurgent $\mathrm{Na}^{+}$current $\left(I_{\mathrm{NaR}}\right)^{9,10}$-a transient voltage-dependent influx of $\mathrm{Na}^{+}$ions that occurs during repolarization of the membrane after action potentials ${ }^{11}$. C-terminal peptides of $\beta 4$ may act as a blocking protein in the open $\mathrm{Na}^{+}$channel, inducing $I_{\mathrm{NaR}}$ in Purkinje cells ${ }^{10}$. Furthermore, knockdown of $\operatorname{Scn} 4 b$ in cerebellar granule cells reduces $I_{\mathrm{NaR}}$.

We have been studying the role of $\beta 4$ in the pathogenesis of Huntington disease (HD) and found that it is expressed mainly in striatum. In HD transgenic mice, $\beta 4$ expression is reduced in the early phase of the disease in neurons that express mutant huntingtin $(\mathrm{mHtt})^{12}$. We also found that overexpression of $\beta 4$ induced neurite outgrowth in neuroblastoma cells and increased spine density in hippocampal cultured neurons ${ }^{12,13}$, suggesting a function in cell adhesion as seen for other $\beta$-subunits.

Regarding the localization of $\beta 4$, it was recently reported that $\beta 4$ is enriched in axon initial segments (AIS) and nodes of Ranvier of diverse neuronal types in the brain ${ }^{8}$. However, functional and localization studies have not been conclusive for striatal neurons, which show the highest expression of $\beta 4$ in the nervous system.

In this study, we examine the localization of $\beta 4$ in striatum and other parts of the brain. In cerebellum and spinal cord, $\beta 4$ is localized in AIS and nodes of Ranvier as are other $\beta$-subunits. In striatal projection axons, however, $\beta 4$ is diffusely distributed. We further report that the axons of striatal projection neurons form large, unmyelinated inhibitory fibre bundles, which is an intriguing finding as very little is known about the distribution and importance of unmyelinated fibres in the central nervous system. We further show that $\beta 4$-deficient mice exhibit a reduction of $I_{\mathrm{NaR}}$, disruption of repetitive firing and increased failure rates in medium spiny neurons (MSNs) in the striatum, suggesting that $\beta 4$ serves as a physiological channel modulator in MSNs.

\section{Results}

Unique $\beta 4$ distribution in striatal projection axons. It is well known that VGSCs are highly concentrated at the nodes of Ranvier and AIS in myelinated nerve fibres ${ }^{1}$. To examine whether this is true for $\beta 4$, we first labelled brain sections of wild-type (WT) mice with an antibody specific to the mouse $\beta 4 \mathrm{C}$-terminal peptide (anti-mSCN4B-C) ${ }^{14}$. Dotted $\beta 4$ immunoreactivity was observed in cerebellar white matter and cervical spinal cord (Fig. 1a,b), whereas diffuse $\beta 4$ staining was observed in long and large axon bundles of basal ganglia (Fig. 1c). Next, we performed double staining with anti-SCN4B-C and anti-Kv1.2, a protein of the juxtaparanodal region. As Kv1.2 is also expressed in cerebellar basket cell axon terminals, which project to Purkinje cell AIS ${ }^{15}$, we also used anti-Kv1.2 to detect Purkinje cell AIS. $\beta 4$ proteins

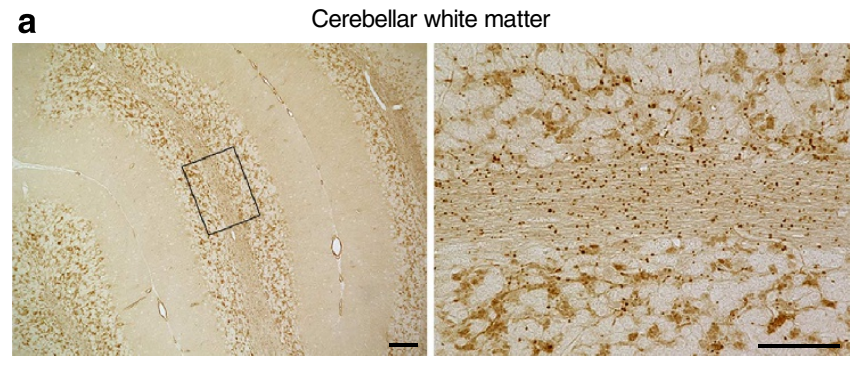

b
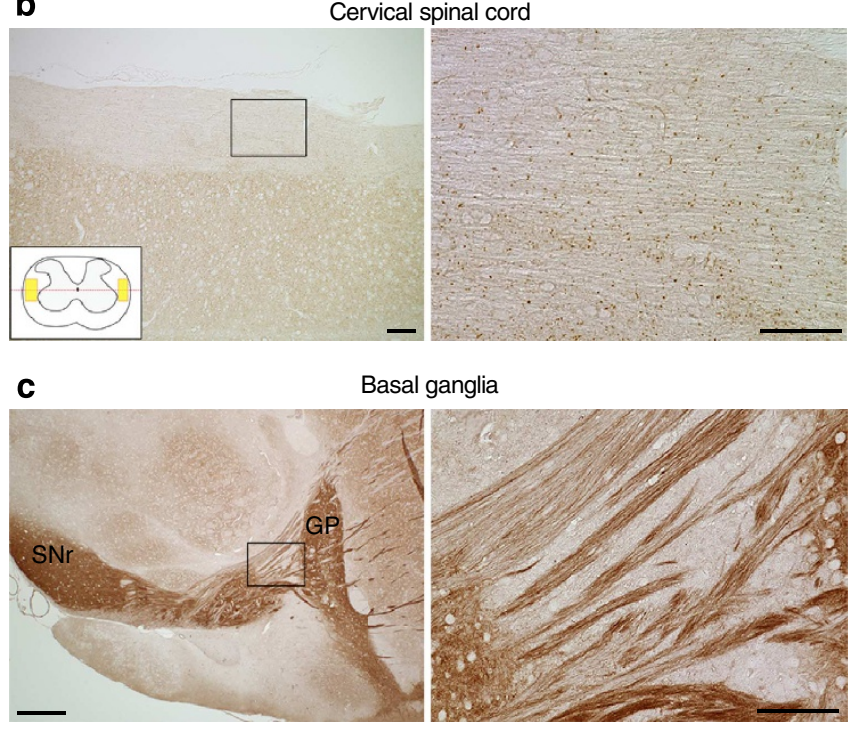

Figure 1 | $\beta 4$ distribution in the mouse brain. $\beta 4$ expression in the 16-week-old mouse brain. Cerebellar white matter (a), lateral funiculus of cervical spinal cord (b) and basal ganglia (c) were stained with anti-SCN4BC. Right panels show higher magnification of boxed area in left panels. Dissected part of cervical spinal cord is illustrated inside box in (b); longitudinal sections were cut from the red dotted line and the yellow boxed area was observed after immunostaining. The boxed area was also examined in the immunofluorescent studies of Fig. 2 (a). Scale bars, $100 \mu \mathrm{m}$ (a,b, left panels; c, right panel); $50 \mu \mathrm{m}$ (a,b, right panels); $500 \mu \mathrm{m}$ (c, left panel). GP, globus pallidus; SNr, substantia nigra pars reticulata.

were clustered at the nodes of Ranvier in cerebellar white matter and spinal cord (Fig. 2a) and at Purkinje cell AIS (Fig. 2b). $\beta 1$ and Nav1.6, which are VGSC subunits ( $\beta$ and $\alpha$, respectively), were also localized in the same regions (Fig. 2a,b).

When we observed $\beta 4$ distributions macroscopically with in situ hybridization and immunohistochemistry, consistent with our previous report ${ }^{12}$, neurons expressing $\beta 4$ mRNA were mainly localized in the striatum, but the strongest $\beta 4$ immunoreactivity was observed in external globus pallidus (GPe) and substantia nigra pars reticulata ( $\mathrm{SNr}$ ) (Figs 1c and 2c). A similar observation was previously reported in human striatum ${ }^{12}$. $\beta 4$ protein seems to be distributed diffusely in axons of striatal projection neurons, which is different from the dotted distribution seen in white matter of the cerebellum and spinal cord (Fig. 1).

$\beta 4$ is enriched in the axons of striatal projection neurons. We expected $\beta 4$ to localize on the axons of striatal projection neurons, based on anti-mSCN4B-C immunoreactivity. In the higher eukaryotes, neurofilaments are the major intermediate filaments in axons. There are three types of neurofilament subunits: heavy (NFH), medium (NFM) and light (NFL) ${ }^{16,17}$. To confirm our assumption that $\beta 4$ is localized along the axons of striatal 
a

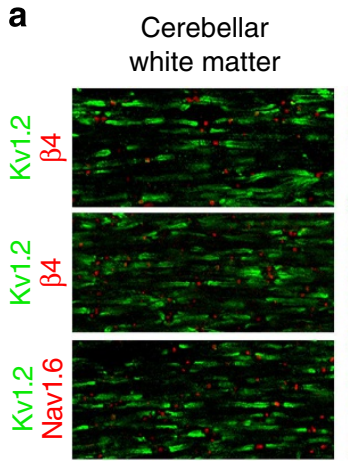

Cerebellar

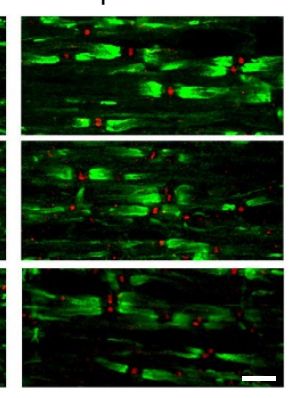

Cervical

spinal cord

d
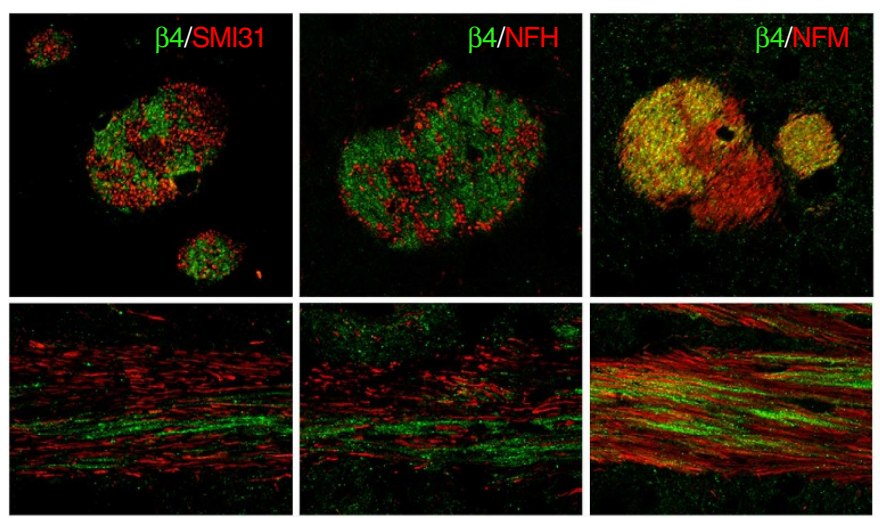

b

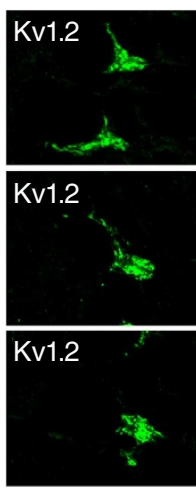

Purkinje cell AIS

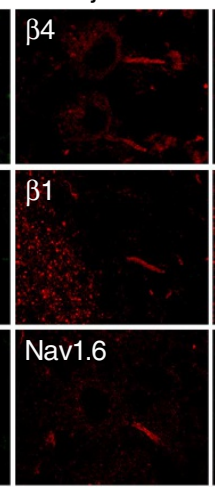

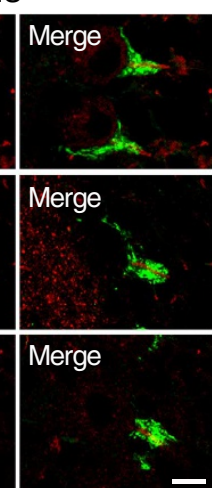

C

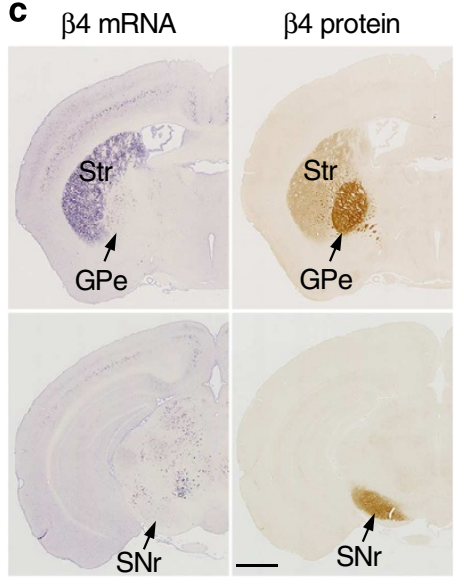

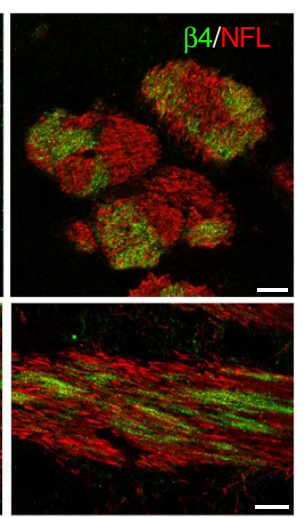

Figure 2 | Characterization of $\boldsymbol{\beta} 4$-expressing axons in the mouse brain. (a,b) 17-week-old mouse brain sections were stained with anti-Kv1.2 (green), anti-mSCN4B-C (top panels, red), anti-mSCN1B-C (middle panels, red), anti-Nav1.6 (bottom panels, red). Observed area is described in Fig. 1a,b. (c) Distributions of $\beta 4$ mRNA and $\beta 4$ protein in the coronal sections of the 12-week-old mouse brain. $\beta 4$ mRNA is expressed mainly in striatum (Str) and strong $\beta 4$ immunoreactivity was observed in the external globus pallidus (GPe) and substantia nigra pars reticulata (SNr). (d) Coronal (upper panels) and sagittal (lower panels) sections of 16-week-old mouse striatum were stained with anti-mSCN4B-C (green), anti-SMI31 (red), anti-NFH (red), anti-NFM (red) and anti-NFL (red). Scale bars, $10 \mu \mathrm{m}(\mathbf{a}, \mathbf{b}, \mathbf{d}) ; 1 \mathrm{~mm}(\mathbf{c})$.

projection neurons, we first performed double staining with antimSCN4B-C and SMI31, which recognizes phosphorylated NFH. Unexpectedly, the $\beta 4$-positive fibres in the striatum were not labelled with SMI31 (Fig. 2d). Another NFH antibody also showed segregated staining from $\beta 4$-positive fibres (Fig. 2d). Immunostaining signals of NFM and NFL in the fascicles showed faint co-localization with anti-SCN4B-C (Fig. 2d), suggesting that $\beta 4$-positive fibres cannot be defined by conventional axonal markers that recognize major cytoskeletal components.

Next, to visualize the axons of striatal projection neurons, and to find direct evidence that $\beta 4$ is expressed in those axons, we generated transgenic mice with the fluorescent marker Venus ${ }^{18}$ under the control of the 9-kb $S c n 4 b$ promoter (Scn $4 b$-Venus, Fig. 3a). We found native Venus fluorescence mainly in the striatum (Fig. 3b), and Venus co-localized with endogenous $\beta 4$ mRNA (Fig. 3c) and DARPP-32, which is a marker of MSNs (Fig. 3d), indicating that $\beta 4$ was expressed in striatal MSNs. Venus protein must therefore be transported from cell bodies to the processes in this transgenic mouse brain. Immunostaining of sagittal brain sections of Scn $4 b$-Venus using anti-GFP and antimSCN4B-C showed that $\beta 4$-positive fibres completely colocalized with Venus-positive fibres, which projected to globus pallidus (GP) and SNr (Fig. 3e,f), suggesting that the fibres are certainly the axons of striatal projection neurons. On the basis of anatomical projection patterns and biochemical differences, MSNs form two pathways. The dopamine D1 receptor (D1R)positive MSNs project to the medial GP and $\mathrm{SNr}$ (direct pathway), whereas dopamine D2 receptor (D2R)-positive MSNs project to the lateral GP (indirect pathway) and co-express enkephalin (PPE encoded by Penk) ${ }^{19}$. To further confirm that $\beta 4$ was expressed in the axons of striatopallidal projection neurons, we used PPE-GFP transgenic mice ${ }^{20}$. Anti-GFP can detect the axons of striatopallidal projection neurons and endogenous $\beta 4$ was co-expressed along those axons (Fig. $3 \mathrm{~g}, \mathrm{~h}$ ). Thus, our results confirmed that $\beta 4$ is strongly expressed in both axons of direct and indirect pathways. To reveal the positional relation with the axons of nigrostriatal neurons, which are afferent inputs arising from the neurons of substantia nigra pars compacta $(\mathrm{SNc})$, we labelled the axons of nigrostriatal neurons with an anti-tyrosine hydroxylase (TH) antibody, which is a marker of dopamine neurons in SNc. TH-positive axons did not overlap with $\beta 4$-positive axons in the striatum and SN (Supplementary Fig. 1), where $\beta 4$-positive axons converge into pars reticulata.

及4-expressing striatal projection axons are unmyelinated. $\mathrm{Na}^{+}$ channel $\alpha$ and $\beta$ subunits are highly recruited in the nodes of Ranvier and AIS in myelinated axons. However, we found diffuse, non-focal $\beta 4$ distribution along the axons of striatal projection neurons, raising the question of whether striatal projection axons could be unmyelinated (that is, lacking nodes of Ranvier). We used Scn $4 b$-Venus mice to investigate this question. Venus codistributed with endogenous $\beta 4$ in striatal axons, which were segregated from NFH-positive axons (Fig. 4a). To detect the 
a

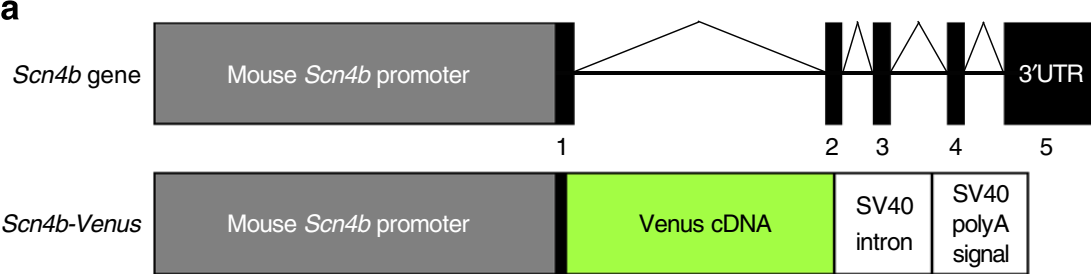

b
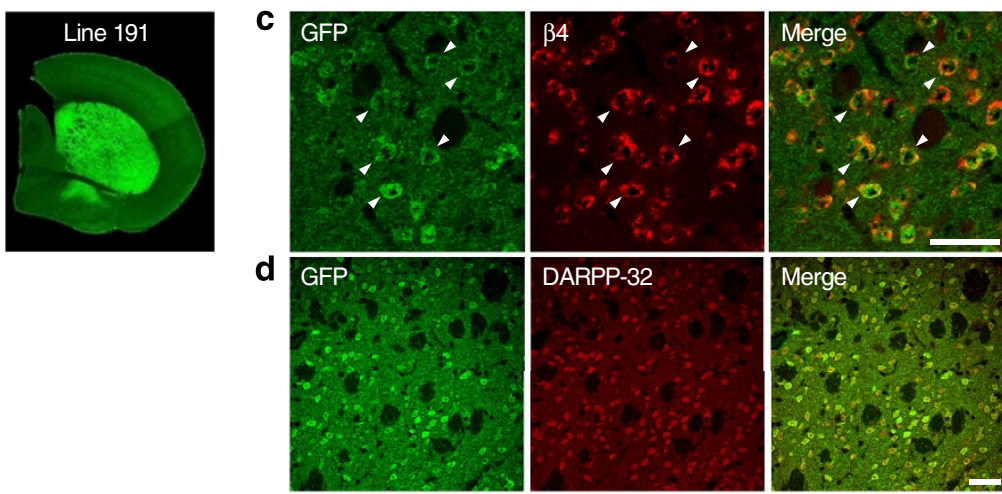

e
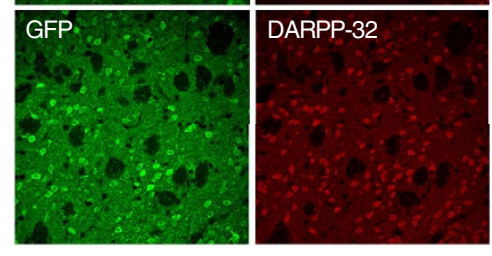

$\beta 4$

Merge
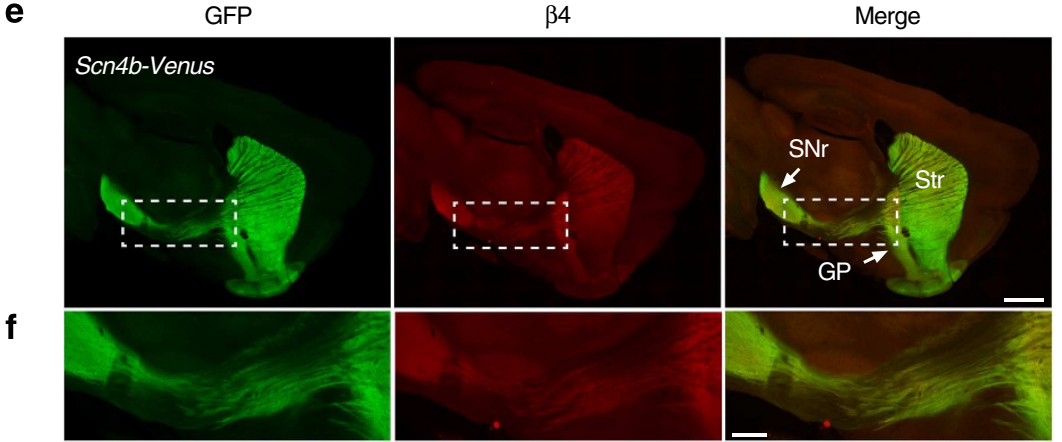

g
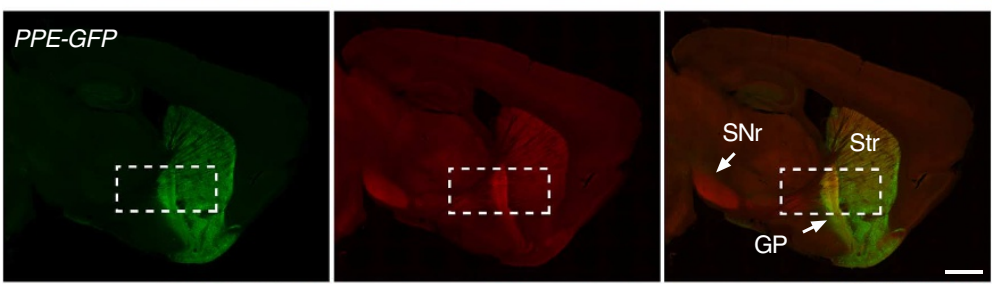

h
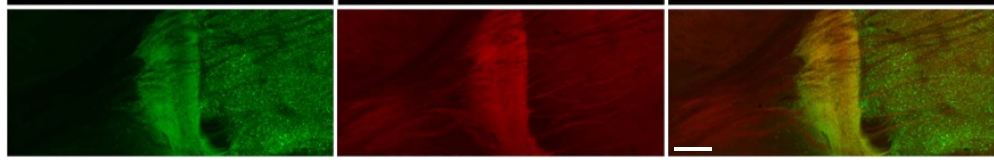

Figure 3 | $\mathbf{~ 4 4}$ is strongly expressed in axon bundles of the striatal projection neuron. (a) Schematic representation of the Scn4b-promoter Venus expression cassette. Venus is expressed under the control of the 9-kb Scn4b-promoter. (b) Native Venus fluorescence was observed in striatum of line 191 Scn $4 b$-Venus transgenic mice. (c) Coronal striatal section of the 8-week-old Scn $4 b$-Venus transgenic mouse was stained by anti-GFP (green) and $\beta 4$ mRNA (red). Arrows show some of the double-labeled neurons. (d) Coronal striatal sections of 12-week-old Scn $4 b$-Venus mouse were stained with anti-GFP (green) to define $\beta 4$-positive cells and anti-DARPP-32 (red) to label MSNs. (e-h) 100- $\mu$ m-thick sagittal brain sections of the 17-weeks-old Scn4b-Venus transgenic mouse (e,f) and the 31-weeks-old PPE-GFP transgenic mouse (g,h) were stained with anti-GFP (green) and anti-mSCN4B-C (red). $(\mathbf{f}, \mathbf{h})$ Higher magnification of the boxed areas in $\mathbf{e}$ and $\mathbf{g}$, respectively. Scale bars, $50 \mu \mathrm{m}(\mathbf{c}, \mathbf{d}) ; 1 \mathrm{~mm}(\mathbf{e}, \mathbf{g}) ; 300 \mu \mathrm{m}(\mathbf{f}, \mathbf{h})$. GP, globus pallidus; SNr, substantia nigra pars reticulata; Str, striatum.

nodes of Ranvier, sagittal Scn $4 b$-Venus striatal sections were stained with anti-Nav1.6 (ref. 21) (nodal protein) and anti-Caspr (paranodal protein). Nodes of Ranvier were identified almost exclusively on NFH-positive axons, but not on Venus-positive axons (Figs $4 \mathrm{~b}, \mathrm{c}$ and $5 \mathrm{a}, \mathrm{b}$ ), suggesting that $\beta 4$ expressing striatal projection axons could be unmyelinated. To further confirm this, we performed immunostaining with $\beta 4$ and MBP, a major constituent of the myelin sheath, and we found the segregation of those stainings (Figs $4 \mathrm{~d}$ and $5 \mathrm{c}-\mathrm{e}$ ). For direct evidence that $\beta 4$-expressing striatal projection axons are unmyelinated, we performed EM and immunoEM analysis. The fascicles of striatal projection fibres in the striatum and SN were composed of a large number of unmyelinated axons (Supplementary Fig. 2), and the unmyelinated axons were labelled by anti-mSCN4B-C (Fig. 4e). 


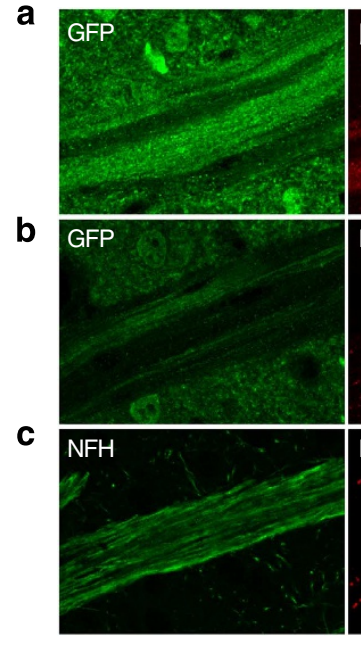

d
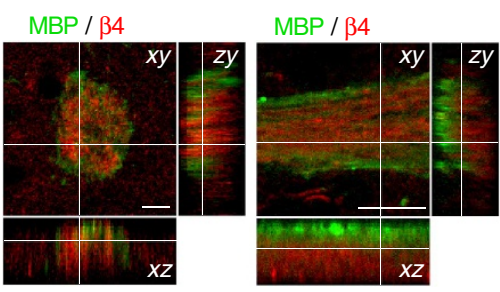

Nav1.6
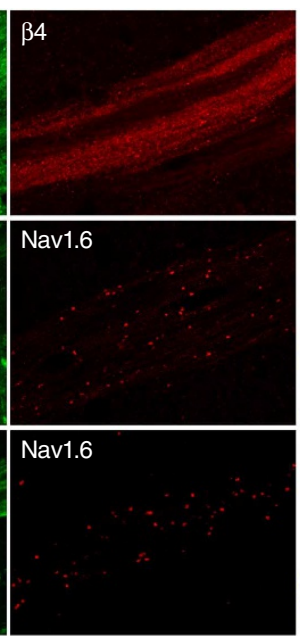

e
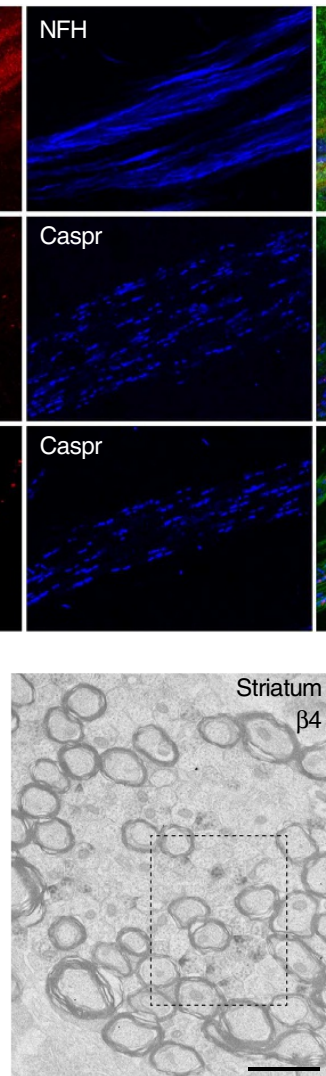

\section{Caspr}
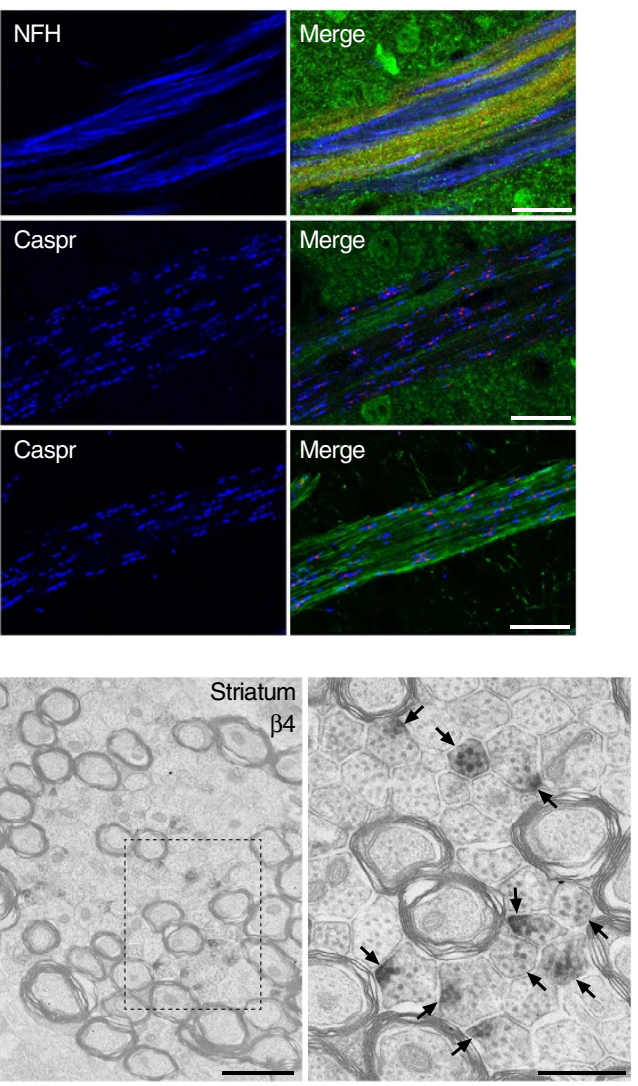

h

$\beta 4$ distribution in CNS
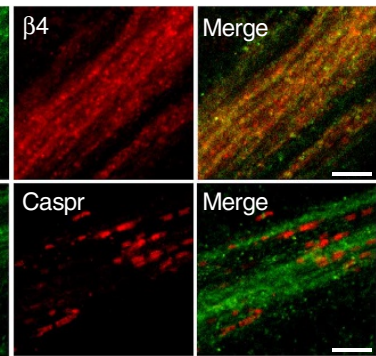

Typical sodium channel subunits localization

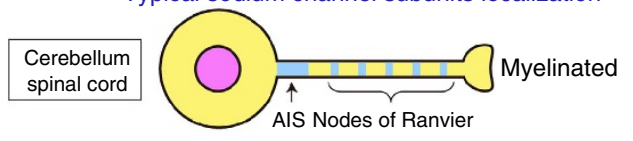

34-specific localization

Striatum

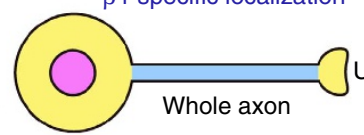

Unmyelinated

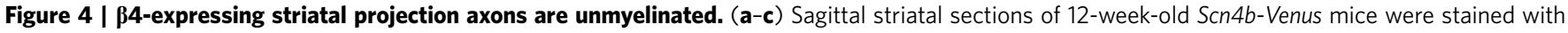
the following sets of antibodies: (a) anti-GFP (green) to detect Venus-positive fibres, anti-mSCN4B-C (red), anti-NFH (blue); (b) anti-GFP (green), anti-Nav1.6 (red), anti-Caspr (blue); (c) anti-NFH (green), anti-Nav1.6 (red), anti-Caspr (blue). (d) Z-stack confocal immunofluorescent images of the fascicles in 15-week-old mouse striatum (left panel, coronal section; right panel, sagittal section), which were stained with anti-MBP (green) and

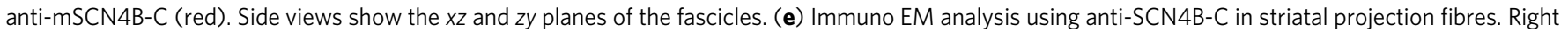
panel shows higher magnification of the boxed area in left panel. Arrows indicate $\beta 4$-labelled axons. (f,g) Sagittal sections of the striatal fascicles in 17-week-old mice were stained with anti-Nav1.2 (green) and anti-mSCN4B-C (red) (f), anti-Nav1.2 (green) and anti-Caspr (red) (g). (h) Schematic representation of the $\beta 4$ distributions in myelinated (cerebellum, spinal cord) and unmyelinated axons (striatum). Scale bars, $20 \mu \mathrm{m}$ (a-d); $1 \mu \mathrm{m}$ (e, left panel); $0.5 \mu \mathrm{m}$ (e, right panel); $5 \mu \mathrm{m}(\mathbf{f}, \mathbf{g})$.

$\beta 4$ immunoreactivity tended to concentrate at the edges of unmyelinated axons (Fig. 4e, right panel). In addition, to determine the $\alpha$-subunit that is coexpressed with $\beta 4$ in striatal projection fibres, we performed immunostaining with antibodies to $\beta 4$ and Nav1.2, another well-known $\alpha$-subunit in the central nervous system $(\mathrm{CNS})^{22,23}$. Nav1.2 was diffusely distributed in the striatal axons and its immunoreactivity co-localized with $\beta 4$ (Fig. 4f). Futhermore, to confirm whether Nav1.2-bearing fibres are unmyelinated, we performed immunostaining with antiNav1.2 and anti-Caspr; Nav1.2 was not co-localized with Caspr (Fig. $4 \mathrm{~g}$ ). These results suggest that Nav 1.2 is a major $\alpha$-subunit of unmyelinated striatal projection fibres.

Taken together, our results demonstrate that $\beta 4$-expressing striatal projection axons are unmyelinated. We identified two $\beta 4$ distribution patterns as follows: in myelinated axons (cerebellum and spinal cord), $\beta 4$ is recruited to the nodes of Ranvier and AIS, whereas in unmyelinated axons (striatum), $\beta 4$ is diffusely distributed along the axons (Fig. 4h).

Establishing a $\beta 4$-deficient mouse. In the CNS, $\beta 4$ is most highly expressed in the striatum, although the role of $\beta 4$ protein in the striatum remains unclear. To address this, we generated $S c n 4 b$-null mice with or without mCherry-V5-His and neomycin-resistant gene cassettes, which are described as $\operatorname{Scn} 4 b^{-/-(m c)}$ and $\operatorname{Scn} 4 b^{-/-}$ mice, respectively (Fig. 6a). Immunoblotting of whole-brain lysate using polyclonal anti-mSCN4B-C and monoclonal anti-hSCN4B-C (7D7F10) (Supplementary Fig. 3) revealed depletion of $\beta 4$ 
a

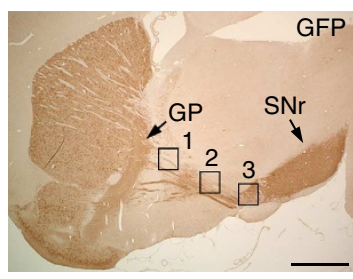

C

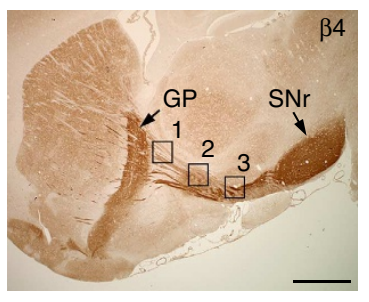

b Striatonigral fibre

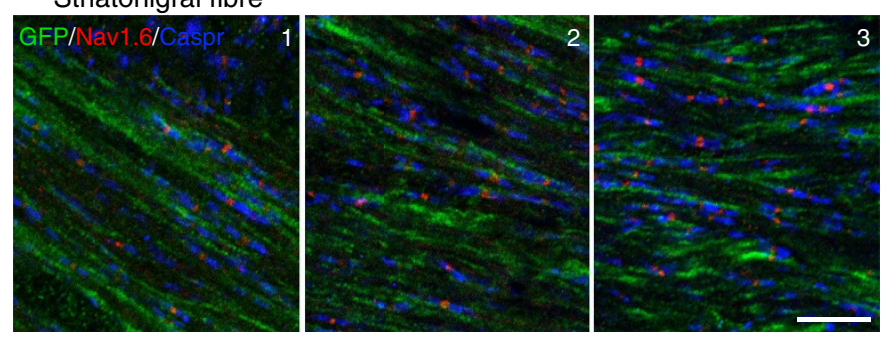

d Striatonigral fibre
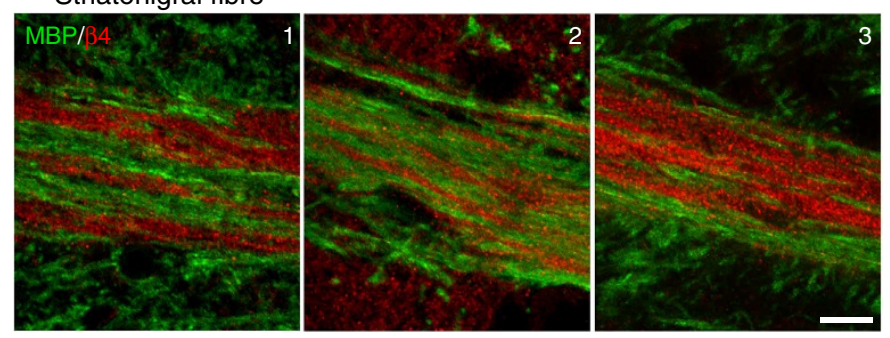

e

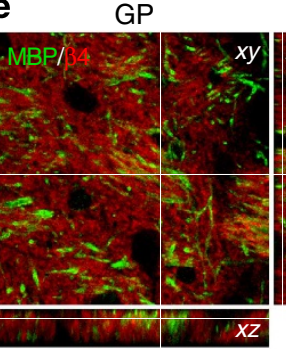

$\mathrm{SNr}$

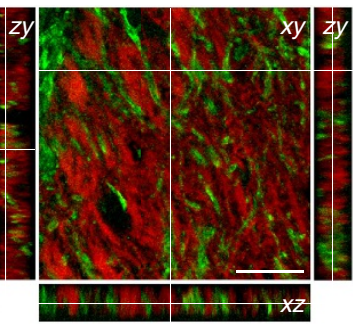

Figure 5 | Striatonigral fibres show the features of unmyelinated axons along the fibres. (a) Sagittal brain section of 12-week-old Scn4b-Venus mouse stained with anti-GFP to observe Venus-positive $\beta 4$ expressing axons. Boxed areas are the approximate examined regions of immunofluorescence results in (b). (b) Sagittal brain sections of 12-week-old Scn4b-Venus mouse stained with anti-GFP (green), anti-Nav1.6 (red) and anti-Caspr (blue). (c) Sagittal brain section of 12-week-old mouse stained with anti-mSCN4B-C. Boxed areas are the approximate examined regions of immunofluorescence results in (d). (d,e) Sagittal brain sections of 15- to 17-week-old mice stained with anti-MBP (green) and anti-mSCN4B-C (red). (e) Z-stack confocal immunofluorescence images of GP and SNr. Side views are examined the $x z$ and zy planes. Scale bar, $1 \mathrm{~mm}(\mathbf{a}, \mathbf{c}) ; 10 \mu \mathrm{m}(\mathbf{b}, \mathbf{d}) ; 20 \mu \mathrm{m}(\mathbf{e})$. GP, globus pallidus; SNr, substantia nigra pars reticulata.

expression in both $S c n 4 b^{-/-(m c)}$ and $S c n 4 b^{-/-}$mice (Supplementary Fig. 4a). In situ hybridization and immunohistochemistry showed that $\beta 4$ mRNA and $\beta 4$ protein expression were lost in the striatum of $S c n 4 b^{-/-}$mice (Supplementary Fig. $4 \mathrm{~b}$ ).

As $\mathrm{Na}^{+}$channels comprise a pore-forming $\alpha$-subunit and two auxiliary $\beta$-subunits, it is possible that another paired $\beta$-subunit may compensate for the loss of $\beta 4$ expression. Western blot analysis using antibodies specific to $\beta$-subunits showed that $\beta 1$ protein levels of $S c n 4 b^{-/-(m c)}$ were slightly upregulated in the spinal cord and cerebellum, but not in the striatum and cortex (Fig. 6b,c). $\beta 2$ levels of $S c n 4 b^{-/-(m c)}$ mice were slightly lower in the spinal cord and cerebellum, and $\beta 3$ levels were not altered in $S c n 4 b^{-/-(m c)}$ mice. These results suggest that only $\beta 1$ shows compensatory upregulation in a region-specific manner. Furthermore, we examined whether compensatory localization changes occurred in the brains of Scn $4 b$-null mice, using in situ hybridization of $\beta$-subunits. No localization changes were seen in the brains of $S c n 4 b^{-/-(m c)}$ mice (Fig. 6d).

$S c n 4 b^{-/}$mice showed sudden unexpected death without apparent abnormality such as seizure (Fig. 6e). We observed a subtle tremor-like phenotype in the $S c n 4 b$-null mice while holding them. To measure this objectively, we used an accelerometer and found a high-frequency (approximately $20-40 \mathrm{~Hz}$ ) tremor-like movement in 12 -week-old Scn $4 b^{-1-}$ mice (Supplementary Fig. 4c,d), indicating that loss of $\beta 4$ induced the tremor-like phenotype.

Effect of $S c n 4 b$ ablation on striatal projection fibres. $\beta$-subunits are members of the IgCAM family and participate in cell adhesion-related activities through their extracellular domain ${ }^{2} . \beta 1$ and $\beta 2$ interact in a trans-homophilic manner, and it leads to aggregation of cultured cells and ankyrin recruitment to sites of cell-cell contact ${ }^{24}$, suggesting that homophilic dimer formation could have a role in cell adhesion. Thus, in addition to modulating $\mathrm{Na}^{+}$channel activity, $\beta 4$ potentially serves as a CAM through its extracellular domain. However, $\beta$ subunits are cleaved by $\beta$ - and $\gamma$-secretase family proteins ${ }^{14}$ and the extracellular domain could be released. Thus, we first confirmed the existence of the extracellular domain of $\beta 4$ in striatal projection fibres. Immunofluorescence results showed that an antibody specific to the extracellular domain of $\beta 4$ (antimSCN4B-EC) completely co-localized with 7D7F10, an antibody that recognizes the $C$ terminus of $\beta 4$, in striatal projection fibres (Fig. 7a and Supplementary Fig. 3). This result indicates the existence of an extracellular domain of $\beta 4$ in striatal projection fibres. Next we performed western blot analysis in an undenatured condition to examine the homophilic interaction of 
a

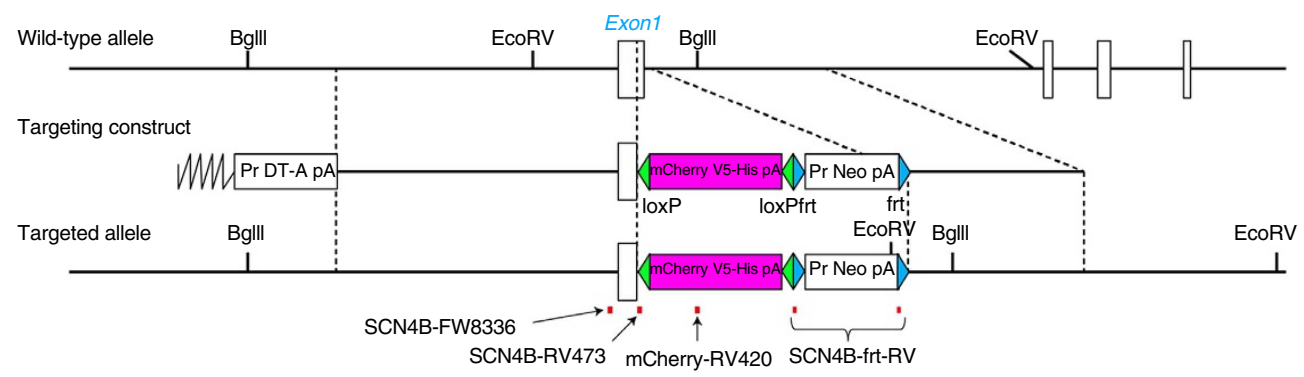

b

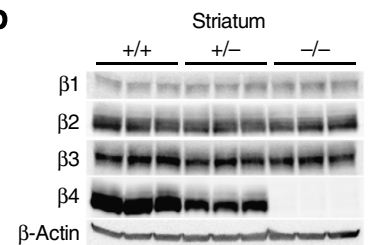

Spinal cord

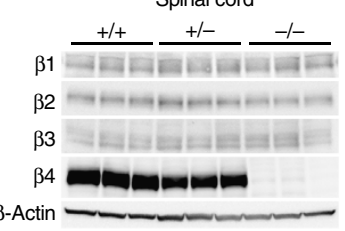

C
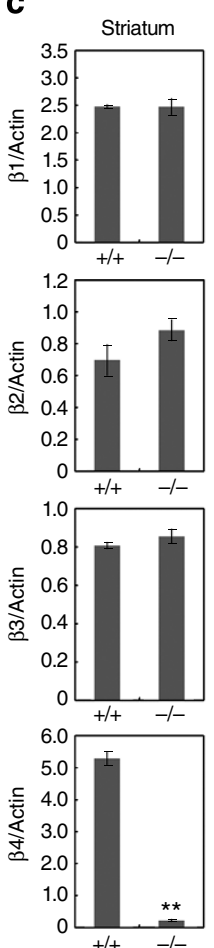
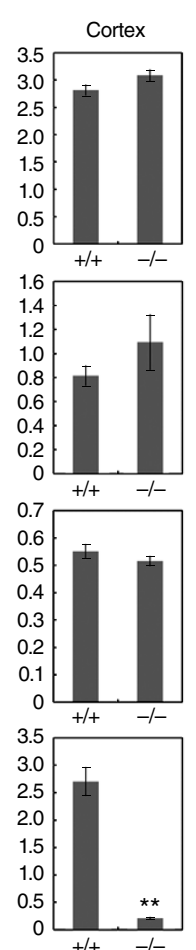

Cortex

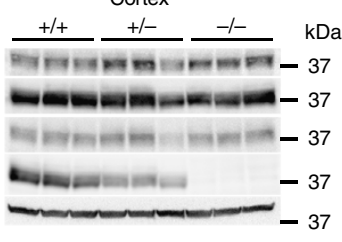

Cerebellum

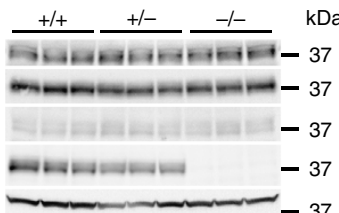

d

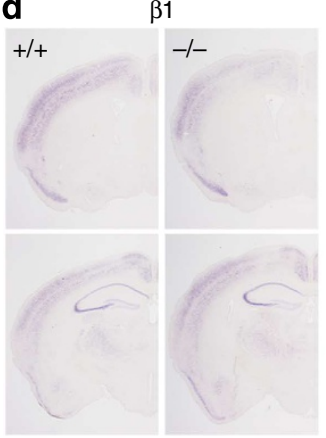

$\beta 3$

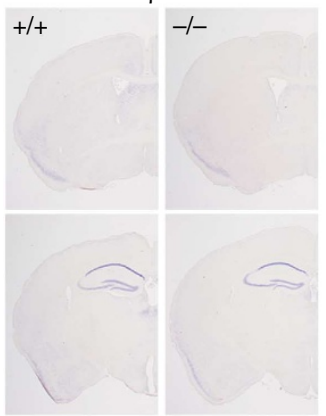

$\beta 2$

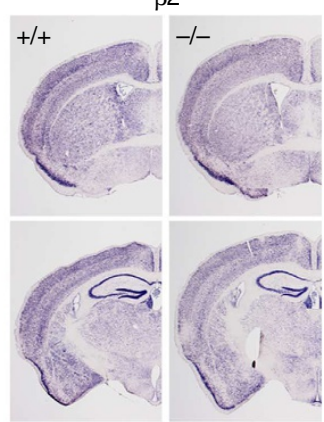

$\beta 4$

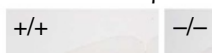

e
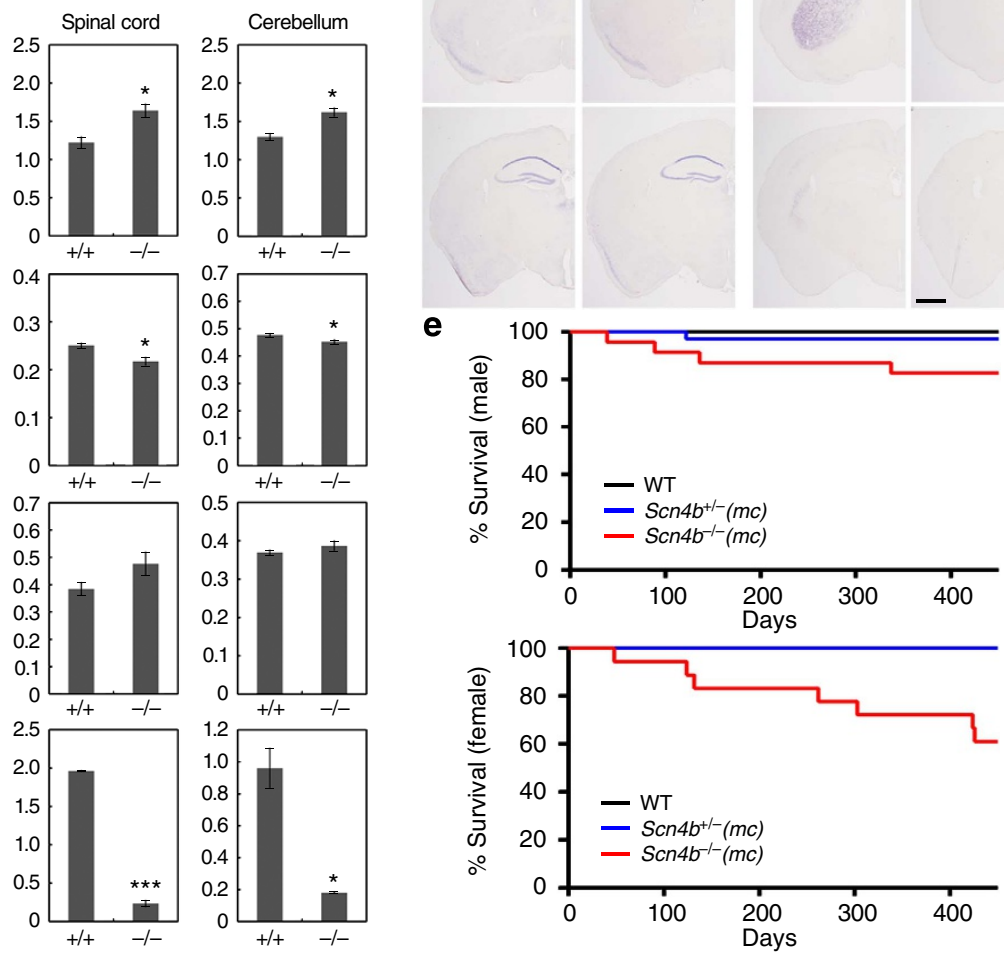

Figure 6 | Generation and characterization of Scn4b-null mice. (a) Diagram of the targeting strategy to ablate Scn4b. Homologous recombination of the targeting construct at the $\mathrm{Scn} 4 \mathrm{~b}$ gene locus resulted in the targeted allele in which the last coding region of exon1 is replaced by $\mathrm{mCherry-V5-His}$ and neomycin-resistant gene cassettes. The targeting construct includes LoxP sites (green triangles) that flank mCherry-V5-His cassette and FRT sites (blue triangles) that flank neomycin-resistant gene cassette. The mCherry-V5-His cassette and neomycin-resistant gene cassette were removed by crossbreeding with a CAG-Cre deleter mouse and a CAG-FLPe deleter mouse, respectively. The regions of genotyping primers are shown as red lines.

(b) Western blot analysis of sodium channel $\beta$-subunits. Membrane fractions ( $20 \mu \mathrm{g})$ of the striatum, cortex, spinal cord and cerebellum from 33 -week-old WT $(+/+)$, heterozygous $(+/-)$ and homozygous $(-/-) \operatorname{Scn} 4 b^{(m c)}$ mutant mice were immunoblotted using antibodies specific to $\beta$-subunits. $\beta$-Actin was used as a loading control. (c) Expression levels of $\beta 1-4$ were quantified. Data are presented as mean \pm s.e.m. ( $n=3$ for each genotype). ${ }^{\star} P<0.05,{ }^{\star \star} P<0.01,{ }^{\star \star \star} P<0.001$, unpaired Student's $t$-test for $\beta 1-3$; unpaired $t$ test with Welch's correction for $\beta 4$. (d) In situ hybridization using cRNA probes of $\beta$ subunits in WT $(+/+)$ and $\operatorname{Scn} 4 b^{-/-(m c)}(-/-)$ mouse brains. Scale bar, $1 \mathrm{~mm}$. (e) Kaplan-Meier survival curves showed sudden unexpected death of male (upper panel) and female (lower panel) $S c n 4 b^{(m c)}$ mutant mice (male, $n=17$ for WT; $n=34$ for $S c n 4 b^{+/-(m c)} ; n=23$ for Scn $4 b^{-/-(m c)}$. female, $n=20$ for WT; $n=14$ for Scn $4 b^{+/-(m c)} ; n=18$ for Scn4b-/-(mc) ). $P=0.0231$ (male) and $P=0.0005$ (female), log-rank test. 
a $\mathrm{hSCN} 4 \mathrm{~B}-\mathrm{C}$

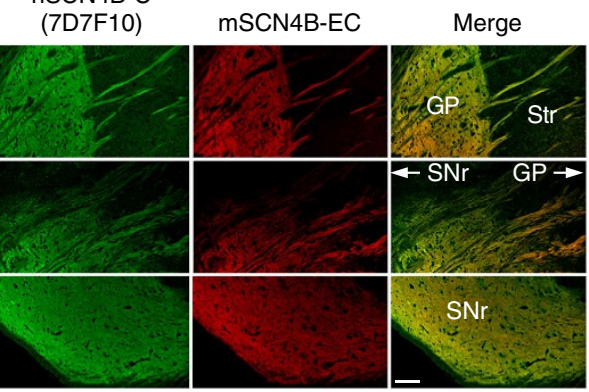

b

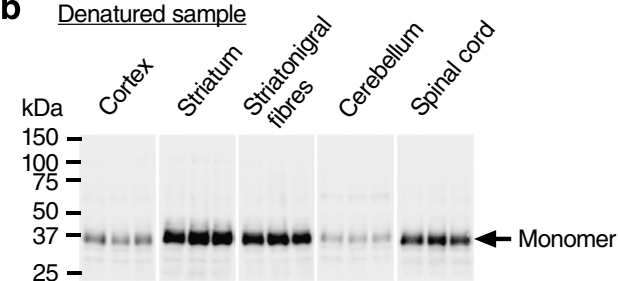

$25-$

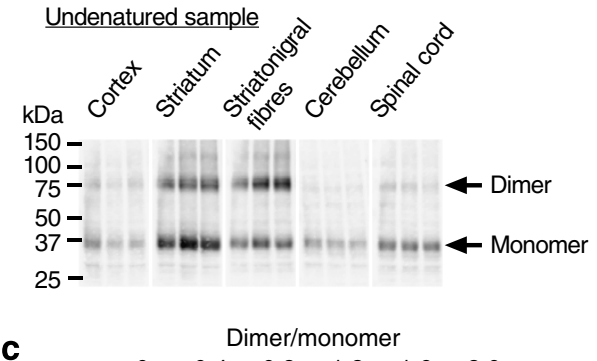

c

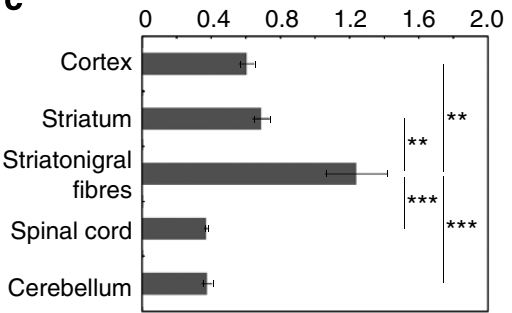

d

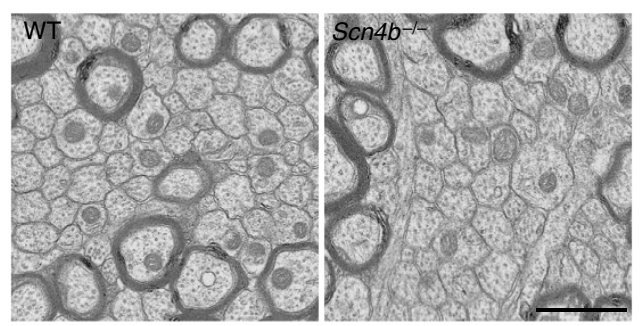

e

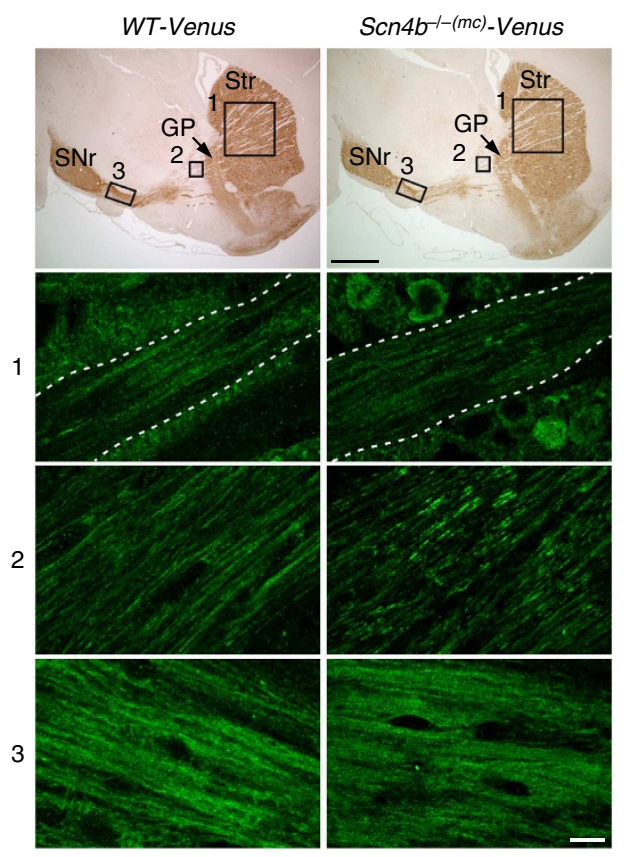

Figure 7 | Fasciculation of the unmyelinated axons in the striatum is preserved in Scn4b-/- mice. (a) Striatonigral fibres of sagittal brain sections of 12-week-old mice were stained with anti-hSCN4B-C (7D7F10) (green) and anti-mSCN4B-EC antiserum (red). (b) Denatured and undenatured brain lysates $(20 \mu \mathrm{g})$ prepared from the cortex, striatum, striatonigral fibres, cerebellum and spinal cord of 12- to 17-week-old Scn4b-Venus mice were immunoblotted with anti-mSCN4B-C. (c) Ratio of $\beta 4$ dimer to $\beta 4$ monomer levels was calculated. Data are presented as mean \pm s.e.m. $(n=3)$. ${ }^{\star \star} P<0.01$, ${ }^{\star \star \star} P<0.001$, one-way ANOVA followed by Tukey's post hoc test. (d) Electron micrographs of cross-sectioned striatal projection fibres in the striatum of 40-week-old WT and Scn4b-/- mice. (e) Immunostaining of sagittal brain sections from 12-week-old WT-Venus and Scn4b- $/$-(mc)-Venus mice with anti-GFP. Top panels are macro view of sagittal brain sections. Boxed areas are the approximate examined regions of immunofluorescence results of the lower panels (1-3). The dotted lines in panel 1 are the outline of the examined axon fascicle. Scale bars, $100 \mu \mathrm{m}(\mathbf{a}) ; 1 \mu \mathrm{m}(\mathbf{d}) ; 1 \mathrm{~mm},(\mathbf{e}$, top panels); $10 \mu \mathrm{m}$ (e, bottom 1-3 panels). GP, globus pallidus; SNr, substantia nigra pars reticulata; Str, striatum.

$\beta 4$. To visualize and dissect striatonigral fibres, we used Scn $4 b$ Venus mice. In the undenatured condition, we found significantly increased dimer formation of $\beta 4$ in striatonigral fibres compared with other brain regions (Fig. $7 b, c$ ), suggesting that homophilic $\beta 4$ interaction might occur between unmyelinated striatal projection axons. Furthermore, the result raised the possibility that the homophilic interaction of $\beta 4$ seems to play a role in fasciculation and pathfinding of striatal projection fibres. To examine the role of $\beta 4$ in striatal projection fibres, we observed organization of the fascicles of striatal projection neurons in $\operatorname{Scn} 4 b^{-/-}$mice by EM. In addition, we performed anti-GFP staining to observe the pathfinding of striatal projection fibres in $S c n 4 b^{-/-(m c)}$-Venus mice. However, there were no obvious changes evident in the EM analysis of $S c n 4 b^{-/-}$mice
(Fig. 7d) and anti-GFP staining of striatal projection fibres in Scn $4 b^{-/-(m c)}$-Venus mice (Fig. 7e).

Effect of $S c n 4 b$ loss on channel function in the striatum. To investigate whether $\beta 4$ indeed regulates $I_{\mathrm{NaR}}$ in vivo, we performed electrophysiological analysis of MSNs from the striatum. Medium-sized cells ( $\sim 10 \mu \mathrm{m}$ in diameter) isolated from the striatal regions were used for whole-cell voltage clamp recordings of $\mathrm{Na}^{+}$currents (Fig. 8a). Most of them were considered to be the projection neurons of the striatum, MSNs, because the other medium-sized GABAergic interneurons such as parvalbumincontaining fast-spiking (FS) neurons and somatostatin/nitric oxide synthase-containing low-threshold spike (LTS) neurons 
a
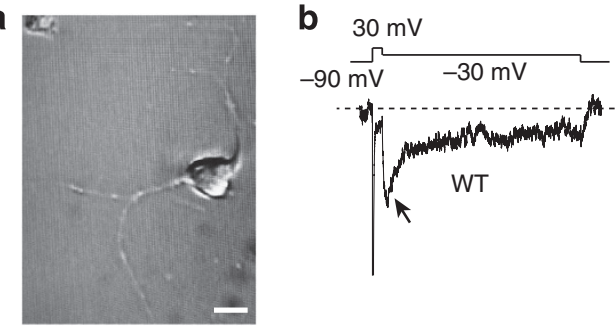

d

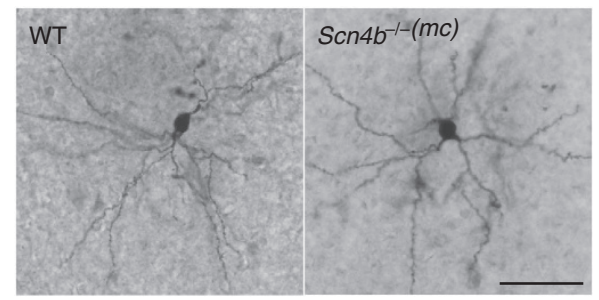

f

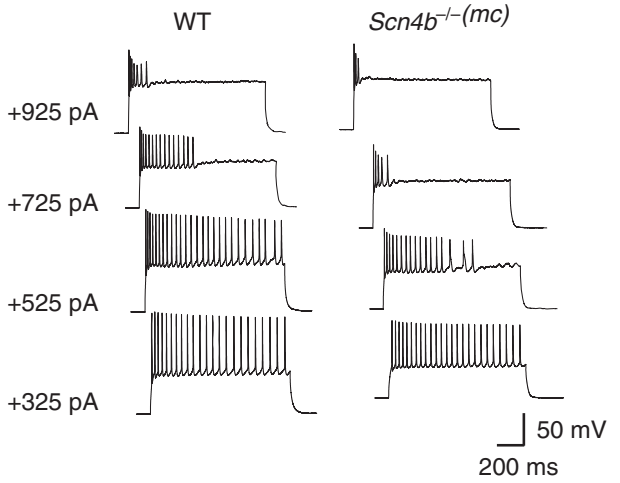

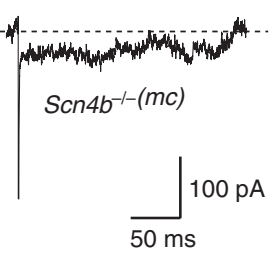

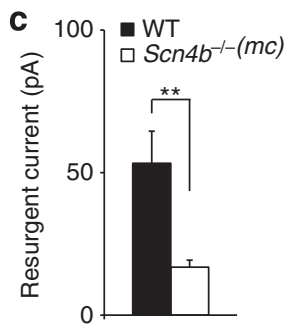

e
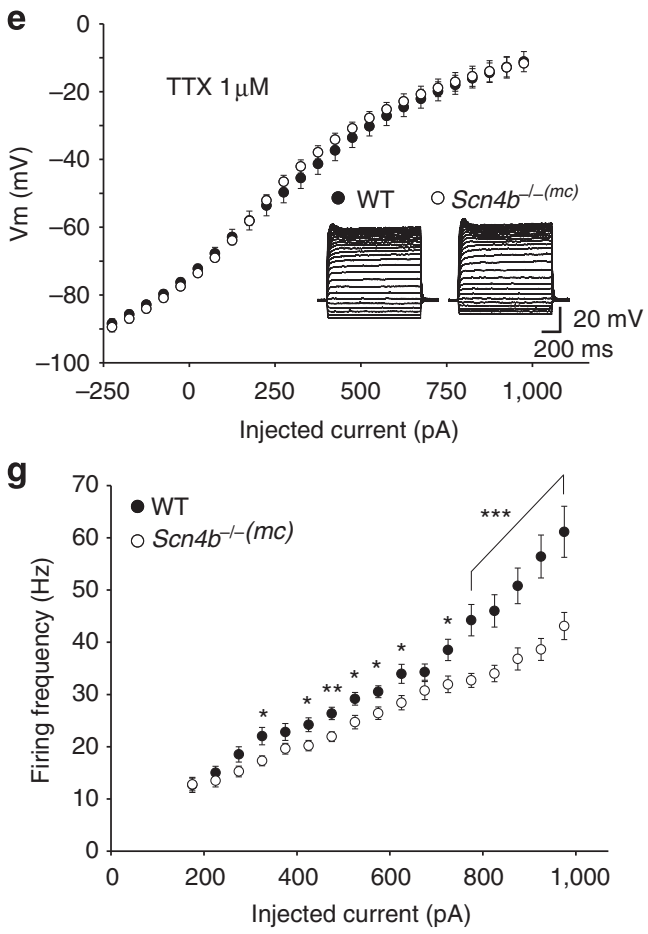

Figure 8 | Depletion of $\boldsymbol{\beta 4}$ decreased resurgent $\mathbf{N a}^{+}$current and compromised repetitive firing property in $\mathbf{M S N s . ~ ( a ) ~ A ~ p h o t o g r a p h ~ s h o w i n g ~ a n ~}$ isolated medium-sized neuron taken from the striatum. (b) Transient, persistent and resurgent $\mathrm{Na}^{+}$currents in a WT cell and a Scn4b- $/-(\mathrm{mc})$ cell. Tetrodotoxin-sensitive $\mathrm{Na}^{+}$currents were evoked by a 10 - $\mathrm{ms}$ depolarization from $-90 \mathrm{mV}$ to $+30 \mathrm{mV}$, followed by a 200 - $\mathrm{ms}$ repolarization to $-30 \mathrm{mV}$. Arrow shows the peak of the resurgent current. Transient $\mathrm{Na}^{+}$currents were truncated. (c) Resurgent $\mathrm{Na}^{+}$current was significantly reduced in $\mathrm{Scn} 4 b^{-/-(m c)}$ mice relative to their WT littermates. Data are presented as mean \pm s.e.m. ( $n=11$ slices from 4 WT; $n=22$ slices from $5 \mathrm{Scn} 4 b^{-/}-(\mathrm{mc})$ ) ${ }^{\star \star} P<0.01$, unpaired Student's $t$-test. (d) Each photograph shows a biocytin-filled and stained MSN in a brain slice taken from a WT or Scn4b ${ }^{-/-(m c)}$ mouse. (e) Composite current-voltage relationship for MSNs from WT and Scn $4 b^{-/-(\mathrm{mc})}$ mice recorded in the presence of tetrodotoxin (TTX $1 \mu M$ ). Data are presented as mean \pm s.e.m. ( $n=15$ slices from 2 mice per genotype). $P>0.05$, unpaired Student's $t$-test. (f) Spike discharge in response to current pulses of increasing intensity for a WT and $S c n 4 b^{-/-(m c)}$ neuron. Note the strong reduction in the amplitude and frequency of spikes and the duration of repetitive firing for mutant compared with WT. (g) Average firing frequency was plotted as a function of step current injection. $\beta 4$ is required for normal excitability in MSNs. Data are presented as mean \pm s.e.m. ( $775 \mathrm{pA}, n=50$ slices from WT; $n=57$ slices from Scn4b-/-(mc); 825 and $875 \mathrm{pA}$, $n=50$ slices from WT; $n=57$ slices from Scn4b-/-(mc); 925 and $975 p A, n=49$ slices from WT; $n=56$ slices from Scn4b-/ - (mc), the slices were prepared from 6 mice per genotype). ${ }^{\star} P<0.05$, ${ }^{\star \star} P<0.01$, and ${ }^{\star \star \star} P<0.001$, unpaired Student's $t$-test. Scale bars, $10 \mu \mathrm{m}(\mathbf{a}) ; 50 \mu \mathrm{m}(\mathbf{d})$.

comprise only a small percentage of the striatal neuron population.

TTX-sensitive $\mathrm{Na}^{+}$currents were evoked by a 10 -ms depolarization from $-90 \mathrm{mV}$ to $+30 \mathrm{mV}$, followed by a $200-$ $\mathrm{ms}$ repolarization to $-30 \mathrm{mV}$. The initial step depolarization to $+30 \mathrm{mV}$ evoked a transient $\mathrm{Na}^{+}$current $\left(I_{\mathrm{NaT}}\right)$, which was followed by a persistent $\left(I_{\mathrm{NaP}}\right)$ and $I_{\mathrm{NaR}}$ at repolarization to $-30 \mathrm{mV}$. The amplitude of $I_{\mathrm{NaR}}$ was calculated as the peak current minus the amplitude of the current remaining at the end of the repolarizing pulse, the $I_{\mathrm{NaP}}$ (Fig. 8b). $I_{\mathrm{NaR}}$ in cells taken from WT mice was significantly larger than that in $S c n 4 b^{-/-(m c)}$ cells (Fig. $8 \mathrm{c}$ and Table 1a, $P<0.01$ ). By contrast, there were no statistical differences in $I_{\mathrm{NaT}}$ or $I_{\mathrm{NaP}}$ between WT and $S c n 4 b^{-/-(m c)}$ mice (Table $\left.1 \mathrm{~b}, \mathrm{c}\right)$. Thus, depletion of $\beta 4$ significantly reduced the amplitude of $I_{\mathrm{NaR}}$ in MSNs.
Reduction of $I_{\mathrm{NaR}}$ disrupts repetitive firing. We therefore tested whether depletion of $\beta 4$ altered the electrophysiological properties of MSNs in whole-cell current clamp recordings in slice preparation. Experiments were performed in the presence of 2-amino-5-phosphonovaleric acid (APV, $50 \mu \mathrm{M})$, 6-cyano-7nitroquinoxaline-2,3-dione (CNQX, $10 \mu \mathrm{M})$ and picrotoxin (PTX, $100 \mu \mathrm{M}$ ) to block glutamatergic and GABAergic synaptic transmission. Striatal MSNs showed a delayed spike firing in response to near-threshold depolarizing current pulses and a marked inward rectification to hyperpolarizing current pulses. Some of the recorded neurons were intracellularly injected with biocytin and stained to morphologically confirm their cell type at the end of the recording period (Fig. 8d). There was no discernible morphological difference between WT and $S c n 4 b^{-/-(m c)}$ mice. Likewise, no significant differences were 
Table 1 | Electrophysiological results in WT and Scn4b-/-(mc) mice.

\begin{tabular}{|c|c|c|c|c|c|c|}
\hline \multirow[b]{2}{*}{ (a) } & \multirow[b]{2}{*}{ Resurgent $\mathrm{Na}^{+}$current } & \multicolumn{2}{|l|}{ WT } & \multicolumn{2}{|l|}{ Scn4b $b^{-/-(m c)}$} & \multirow[b]{2}{*}{$P<0.01$} \\
\hline & & $53.3 \pm 16.8 \mathrm{pA}$ & $n=11$ & $16.8 \pm 2.5 \mathrm{pA}$ & $n=22$ & \\
\hline (b) & Transient $\mathrm{Na}^{+}$current & $784.7 \pm 99.7 p A$ & $n=11$ & $753.6 \pm 57.6 \mathrm{pA}$ & $n=22$ & $\mathrm{NS}^{\star}$ \\
\hline (c) & Persistent $\mathrm{Na}^{+}$current & $37.7 \pm 7.4 \mathrm{pA}$ & $n=11$ & $26.2 \pm 3.8 \mathrm{pA}$ & $n=22$ & NS \\
\hline (e) & Input resistance & $115.5 \pm 8.4 \mathrm{M} \Omega$ & $n=50$ & $118.3 \pm 6.6 \mathrm{M} \Omega$ & $n=63$ & NS \\
\hline$(f)$ & Spike half-width & $1.2 \pm 0.0 \mathrm{~ms}$ & $n=50$ & $1.2 \pm 0.0 \mathrm{~ms}$ & $n=63$ & NS \\
\hline$(g)$ & $\begin{array}{l}\text { Time constant of membrane potential in response to } \\
-50 \mathrm{pA} \text { current pulse }\end{array}$ & $4.0 \pm 0.3 \mathrm{~ms}$ & $n=50$ & $4.1 \pm 0.2 \mathrm{~ms}$ & $n=63$ & NS \\
\hline \multirow{3}{*}{ (h) } & At $100 \mathrm{~Hz}$ & $23.9 \pm 2.2$ & $n=37$ & $23.8 \pm 2.1$ & $n=46$ & NS \\
\hline & At $133 \mathrm{~Hz}$ & $18.9 \pm 1.8$ & $n=34$ & $18.6 \pm 1.6$ & $n=40$ & NS \\
\hline & At $200 \mathrm{~Hz}$ & $12.6 \pm 1.2$ & $n=34$ & $13.3 \pm 1.3$ & $n=38$ & NS \\
\hline \multirow[t]{3}{*}{ (i) } & Spike number evoked by 20 current pulses of $1 \sim 3 \mathrm{~ms}$ duration & & & & & \\
\hline & $1 \mathrm{nA}$ at $100 \mathrm{~Hz}$ & $14.9 \pm 0.8$ & $n=27$ & $15.0 \pm 0.8$ & $n=21$ & NS \\
\hline & $1 \mathrm{nA}$ at $133 \mathrm{~Hz}$ & $11.2 \pm 0.8$ & $n=22$ & $10.4 \pm 0.4$ & $n=17$ & NS \\
\hline \multirow[t]{7}{*}{ (n) } & Paired pulse ratio of elPSCs & & & & & \\
\hline & $25 \mathrm{~ms}$ interval & $1.18 \pm 0.20$ & $n=17$ & $1.03 \pm 0.24$ & $n=20$ & NS \\
\hline & $50 \mathrm{~ms}$ interval & $1.14 \pm 0.13$ & $n=17$ & $1.02 \pm 0.12$ & $n=20$ & NS \\
\hline & $100 \mathrm{~ms}$ interval & $1.14 \pm 0.15$ & $n=17$ & $1.10 \pm 0.14$ & $n=20$ & NS \\
\hline & $200 \mathrm{~ms}$ interval & $1.09 \pm 0.10$ & $n=17$ & $1.11 \pm 0.12$ & $n=20$ & NS \\
\hline & $500 \mathrm{~ms}$ interval & $0.97 \pm 0.08$ & $n=17$ & $1.05 \pm 0.10$ & $n=20$ & NS \\
\hline & $1,000 \mathrm{~ms}$ interval & $0.98 \pm 0.06$ & $n=17$ & $0.96 \pm 0.07$ & $n=20$ & NS \\
\hline (o) & Failure rates, 20 pulses at $20 \mathrm{~Hz}$ & $0.15 \pm 0.05$ & $n=16$ & $0.31 \pm 0.06$ & $n=19$ & $P<0.05$ \\
\hline
\end{tabular}

found between the two in resting membrane potential (Table 1d), input resistance at $-70 \mathrm{mV}$ (Table 1e), half spike width (Table 1f) or rise time constant at $-80 \mathrm{mV}$ (Table 1g). The voltage-current (V-I) relationship recorded from -90 to $-10 \mathrm{mV}$ in the presence of TTX also revealed no differences between the two (Fig. 8e). Next, we compared repetitive firing properties of MSNs between WT and Scn $4 b^{-/-(m c)}$ mice. To stimulate MSNs with certainty and high frequency, we used two strategies. First, we placed two tungsten or glass electrodes in the striatum, antidromically stimulated axon fibres with 50 pulses of $100-\mu$ s duration and a sufficiently small intensity of $0.2 \sim 1.0 \mathrm{~mA}$ at 100,133 and $200 \mathrm{~Hz}$ and tested how many spikes were evoked in the recorded neurons by 50 electrical stimuli. No differences could be found between the two in this test (Table 1h). Second, we injected 20 current pulses of $1 \sim 3 \mathrm{~ms}$ duration and $1 \mathrm{nA}$ into the cells examined at 100,133 and $200 \mathrm{~Hz}$ and tested how many spikes were evoked. Although we found no statistical differences between the two in spike number (Table 1i), there was a significant difference in the frequency of action potentials spontaneously evoked by current injection of $1 \mathrm{~s}$ duration. We increased the injected current of $1 \mathrm{~s}$ duration from $25 \mathrm{pA}$ up to $975 \mathrm{pA}$ in $50-\mathrm{pA}$ increments to compare average firing frequency between the two. Although rheobase for WT was equivalent to that for $S c n 4 b^{-/-(m c)}$ mice (Table $1 \mathrm{j}$ ), average firing frequency in $S c n 4 b^{-/-(m c)}$ mice was significantly more decreased than that in WT when the injected current was more than $325 \mathrm{pA}$, except for 375 and $675 \mathrm{pA}$ (Fig. 8f,g, $P<0.001$ from 775 to $975 \mathrm{pA}$ ). Thus, it appears that depletion of $\beta 4$ significantly decreases repetitive firing frequency in the face of constant depolarization.

We next examined whether depletion of $\beta 4$ altered conduction velocity in MSNs. First, action potentials were antidromically evoked in striatal cells by electrical stimulation with one or two electrodes placed in the striatum. The distances between the cells recorded and the electrodes were measured using photos taken after the experiments. The conduction velocities were estimated by the distances divided by the latencies of action potentials from stimulus artifacts. We found that the conduction velocities in both WT and $S c n 4 b^{-/-(m c)}$ mice were similar and not significantly different from each other (Table $1 \mathrm{k}$ ). Second, we used sagittal slices obtained from $S c n 4 b^{-/-(m c)}$ mice crossed with $S c n 4 b$-Venus transgenic mice (WT-Venus or $S c n 4 b^{-/-(m c)}$. Venus mice) whose striatonigral pathways were visible under fluorescent microscope with Venus. Two electrodes were placed apart on the bright striatonigral pathways (Fig. 9a) and the inhibitory postsynaptic currents (eIPSCs) evoked by electrical stimulation were measured from the stimulus artefacts to the onset of eIPSCs from nigral neurons in whole-cell voltage-clamp mode (Fig. 9b). Stimulation electrodes and recording patch pipettes were positioned almost linearly, and the distances among them were measured to calculate the conduction velocities (Fig. 9c). Again, there were no significant differences in the conduction velocities between $W T$-Venus and $S c n 4 b^{-/-(m c)}$. Venus mice (Fig. 9d and Table 1l). Estimated synaptic delays of eIPSCs in WT-Venus and Scn4b $b^{-/-(m c)}$-Venus mice were also similar (Table $1 \mathrm{~m}$ ). We also examined paired pulse ratios of eIPSCs and found a tendency to respond more vigorously to the second stimulus given $50 \mathrm{~ms}$ after the first stimulus in the nigral neurons of both types of mice, but no significant differences were found between the two (Fig. 9e and Table 1n). Failure rates significantly increased in Scn $4 b^{-/-(m c)}$-Venus mice compared with WT-Venus mice (Fig. 9f,g and Table 1o).

\section{Discussion}

In this study, we found atypical localization of $\beta 4$ in striatal projection fibres, showing non-focal and diffuse $\beta 4$ distribution 
a

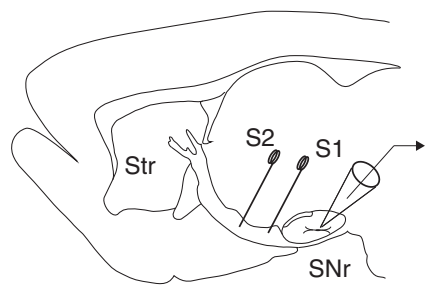

e

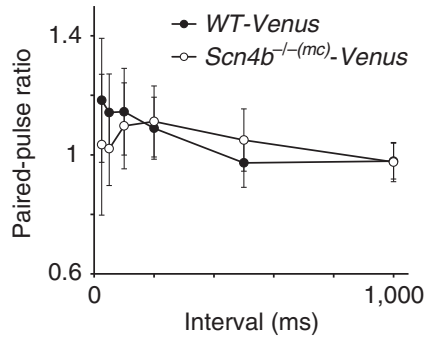

b

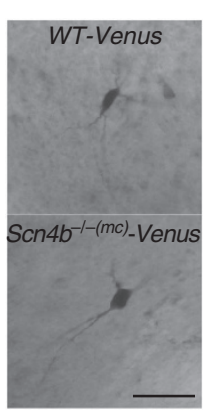

C

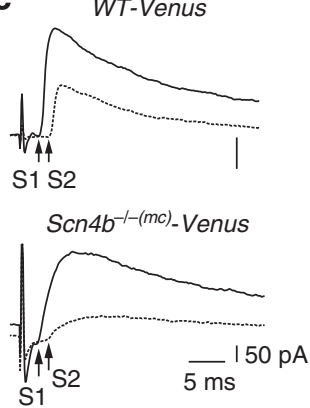

d
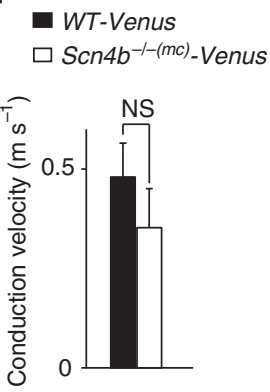

f
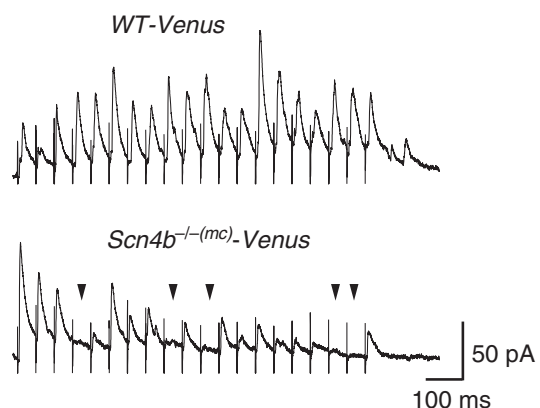

9

$$
\begin{aligned}
& \text { WT-Venus } \\
& \square \text { Scn } 4 b^{-1-(m c)} \text {-Venus }
\end{aligned}
$$

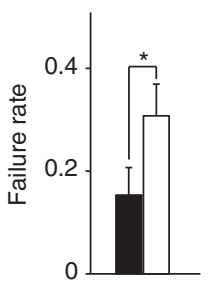

Figure 9 | Deletion of $\mathbf{\beta 4}$ increased failure rates of evoked IPSCs in nigral neurons. (a) Schema showing the recording configuration of nigral neurons in a sagittal slice ( $\mathrm{SNr}=$ substantia nigra pars reticulata; $\mathrm{Str}=$ striatum). Two stimulating electrodes (S1, S2) were placed on the striatonigral pathways. (b) Photographs showing biocytin-filled and stained nigral neurons in a brain slice of a WT-Venus or a Scn $4 b^{-/-(m c)}$-Venus mouse. Scale bar, $50 \mu m$. (c) IPSCs evoked with two electrodes (S1, solid line; S2, dotted line) in nigral neurons of a WT-Venus or a Scn $4 b^{-/-(m c)}$-Venus mouse. Arrows indicate onsets of the elPSCs. (d) Summary of conduction velocities. Data are presented as mean \pm s.e.m. $(n=10$ slices from WT-Venus; $n=11$ slices from $\mathrm{Scn} 4 b^{-/-(m c)}$-Venus, the slices were prepared from six mice per genotype). NS, not significant, $P>0.05$, unpaired Student's $t$-test. (e) Paired pulse ratio of elPSCs. ( $n=17$ slices from WT-Venus; $n=20$ slices from $S c n 4 b^{-/-(m c)}$-Venus, the slices were prepared from five mice per genotype). $P>0.05$, unpaired Student's $t$-test. (f) IPSCs evoked with repetitive stimulation (20 pulses, $20 \mathrm{~Hz}$ ). Arrowheads indicate failures of the elPSCs. Data are presented as mean \pm s.e.m. (g) Summary of the failure rates of the elPSCs. Data are presented as mean \pm s.e.m. $(n=16$ slices from WT-Venus; $n=19$ slices from $S \mathrm{cn} 4 b^{-/-(m c)}$-Venus, the slices were prepared from five mice per genotype). ${ }^{\star} P<0.05$, unpaired Student's $t$-test.

along the axons. Those fibres lack nodes of Ranvier and immunoreactivity of MBP and NFH, and an EM study confirmed they are unmyelinated. Thus, the unique diffuse staining pattern of $\beta 4$ (along with the lack of certain myelinated axonal markers) can positively define $\beta 4$-bearing unmyelinated fibres. Several electron microscopic studies have reported D1R immunoreactivity in myelinated and unmyelinated axons around $\mathrm{SNr}^{25-27}$, and $\mathrm{D} 2 \mathrm{R}$-positive unmyelinated axons were detected in the striatum ${ }^{28}$ and ventral pallidum ${ }^{29}$. These results suggest that striatal projection could include unmyelinated axons. However, due to methodological limitations of those EM studies, it was hard to determine the origin of axons and what portion of the striatal projection fibres contains unmyelinated fibres. We sought to clarify this point using $S c n 4 b$-Venus mice, which express Venus in MSNs and their projection fibres including the direct and indirect pathways. Venus expression completely colocalized with $\beta 4$ diffuse staining, suggesting that virtually all $\beta 4$-expressing projection fibres from striatum are unmylinated. Using PPE-GFP mice, we further confirmed that the indirect pathway is composed of unmyelinated fibres. These results demonstrate the existence of large bundles of unmyelinated projection fibres from the striatum.

The role of unmyelinated fibres in the CNS is not well known. It has been thought that the mammalian CNS had abandoned unmyelinated nerve fibres in favour of myelinated fibres, as unmyelinated fibres are slow-conducting and energetically expensive ${ }^{30}$. However, the preservation of such long, large bundles of unmyelinated fibres as striatal projection fibres suggests potential beneficial effects in the circuit. A massive unmyelinated axonal arbor was reported in the nigrostriatal pathway $^{31}$. We also examined myelination of this pathway by immunohistochemistry, suggesting this pathway could be unmyelinated or partly thin-myelinated (Supplementary Fig. 5). So the main circuit (input and output) in the striatum could have slow conductance. This might be beneficial for motor control and reward processing by the basal ganglia.

In the hippocampus, well-known unmyelinated fibres called mossy fibres originate from granular cells, which show adult neurogenesis; unmyelinated fibres might be beneficial because myelin is a main blocker to regeneration, although it is not known whether neurogenesis occurs in the striatum ${ }^{32}$. Another unique feature of unmyelinated fibres was recently discovered: vesicular release of glutamate from unmyelinated fibres in the corpus callosum, which are responsible for glutamatergic signalling with $\mathrm{NG}^{+}$glia $^{33,34}$. Thus, unmyelinated fibres might mediate the release of neurotransmitters from the axonal surface.

In this study, we found Nav1.2 diffusely localized on these axons, co-localizing with $\beta 4$. Nav1.2 was previously reported to localize in the unmyelinated fibres of optic nerves, hippocampus and cerebellum ${ }^{22,23}$. We also confirmed diffuse Nav1.2 immunoreactivity on the mossy fibres of hippocampus and the parallel fibres of cerebellum (data not shown), suggesting Nav1.2 is diffusely distributed on unmyelinated fibres in CNS including striatal projection fibres. The striatal projection fibres are GABAergic and inhibitory, although many known unmyelinated fibres are glutamatergic and excitatory. Thus, the question arises whether $\beta 4$ is also expressed in those unmyelinated glutamatergic axons. To examine this, we stained the corpus callosum with anti-mSCN4B-C and anti-Nav1.2. 
Diffuse $\beta 4$ staining was not observed in the corpus callosum, but Nav1.2 was diffusely distributed in a portion of corpus callosum axons (Supplementary Fig. 6a,b). Thus, the results suggest that $\beta 4$ is expressed in the GABAergic unmyelinated axons and Nav1.2 seems to be more generally expressed in unmyelinated axons, including those of corpus callosum.

In the present study, we found elevated $\beta 4$ dimer levels in striatonigral fibres. However, there were no overt changes evident in immunostaining and EM studies in the fascicles of striatal projection axons in $S c n 4 b^{-1-}$ mice. It is broadly accepted that $\beta 1$ serves as a $\mathrm{CAM}^{2,4,35}$. During early postnatal development, $\beta 1$ is expressed in the mouse forebrain as early as P1 (ref. 36), but $\beta 4$ expression begins in the mouse brain between P1 and P7 (Supplementary Fig. 7). These results give rise to the possibility that $\beta 4$ might not contribute to pathfinding in early postnatal development, but may play an auxiliary role during later development. It has been proposed that the functions of IgCAMs on the basis of in vitro assay (for example, neurite outgrowth and cell migration) may not be affected in vivo when only one gene is ablated in a knockout mouse, because similar and overlapping functions of IgCAMs provide compensation. NrCAM-null mouse cerebellum showed no marked changes, but $\mathrm{NrCAM}$ and L1 double-knockout mice exhibited severe cerebellar folial defects and size reduction ${ }^{37}$. Thus, the effects of $\beta 4$ ablation in vivo are possibly compensated by other IgCAMs members.

On membrane depolarization, VGSCs first activate (open) and then inactivate (close), carrying the classic 'transient' inward $\mathrm{Na}^{+}$current $\left(I_{\mathrm{NaT}}\right)$. In addition to this rapidly inactivating $I_{\mathrm{NaT}}$, VGSCs generate two distinct inward $\mathrm{Na}^{+}$currents in some neurons: a non-inactivating 'persistent' $\mathrm{Na}^{+}$current $\left(I_{\mathrm{NaP}}\right)$ and a 'resurgent' $\mathrm{Na}^{+}$current $\left(I_{\mathrm{NaR}}\right) \cdot I_{\mathrm{NaP}}$ is activated at sub-threshold potentials of about -60 to $-50 \mathrm{mV}$ and may facilitate bursts of neuronal discharges ${ }^{38} . I_{\mathrm{NaR}}$ is also a transient current generated when action potential generation and channel inactivation $\left(I_{\mathrm{NaT}}\right)$ is followed by membrane repolarization to voltages near -50 or $-60 \mathrm{mV}$ and has been implicated in repetitive action potential discharges of neurons ${ }^{11}$. To date, the most accepted mechanism to explain how $I_{\mathrm{NaR}}$ is produced is an open-channel block by the cytoplasmic tail of an accessory subunit $\beta 4$ of $\mathrm{VGSC}^{9,10}$. Grieco et al. ${ }^{10}$ demonstrated that a free peptide containing the cytoplasmic tail of $\beta 4$ restored the resurgent currents after enzymatic degradation of the endogenous open-channel blocker by trypsin and chymotrypsin in inside-out patches taken from cerebellar Purkinje neurons. Bant and Raman ${ }^{9}$ confirmed their results by showing that the knockdown of $S c n 4 b$ (elimination of $\beta 4$ ) with its siRNA in cultured cerebellar granule neurons led to a loss of $I_{\mathrm{NaR}}$, a reduction of $I_{\mathrm{NaP}}$, a higher rheobase and a decrease in repetitive firing. We previously showed that MSNs of the striatum have $\beta 4$, which is downregulated in HD model mice and in human patients ${ }^{12}$. Therefore, we predicted that the $I_{\mathrm{NaR}}$ would be present in MSNs of WT mice but not in those of Scn $4 b$-null mice. As expected, our electrophysiological analysis using dissociated putative MSNs revealed that the $I_{\mathrm{NaR}}$ of MSNs was significantly reduced in the $S c n 4 b$-null mice compared with WT controls, whereas $I_{\mathrm{NaT}}$ and $I_{\mathrm{NaP}}$ of MSNs of the Scn $4 b$-null and WT mice were not statistically different from each other.

The next question is the physiological relevance of $I_{\mathrm{NaR}}$ in MSNs. It has been proposed that the $I_{\mathrm{NaR}}$ immediately after a spike may promote high-frequency spontaneous firing of neurons $s^{2,39-43}$. Our whole-cell current clamp recordings in brain slices showed that spontaneous firing during sustained depolarization in MSNs of $S c n 4 b$-null mice was significantly attenuated at injected currents of more than $325 \mathrm{pA}$ compared with WT mice, whereas the relationship of membrane potential and injected current in MSNs was almost identical between $S c n 4 b$-null and WT mice. Thus, $\beta 4$ considerably influences excitability of MSNs. $\beta 4$ may enable MSNs to discharge significantly higher-frequency spikes for a long time when MSNs are in the Up-state of -71 to $-40 \mathrm{mV}$ in vivo, which is maintained by a barrage of synaptic excitation ${ }^{44}$. Furthermore, deletion of $\beta 4$ increased failure rates of striatonigral inputs in response to 20-pulse stimulation at $20 \mathrm{~Hz}$. The most general cause of the increased failure rate is reduction of release probability at the presynaptic terminal ${ }^{45}$. In our experiments, the paired pulse ratio was not significantly different between the mutant mice and the WT control mice, so an apparent change of release probability appears unlikely in this case. Another possible factor in transmission failure is collapse of spike propagation. Yang and Wang $^{46}$ demonstrated that spike propagation in axons of Purkinje cells is more reliable during application of anemone toxin II, which blocks inactivation of VGSC and enhances resurgent currents ${ }^{46,47}$. Although it remains to be studied whether $I_{\mathrm{NaR}}$ directly regulates the failure rate, deletion of $\beta 4$ could influence the spike propagation in striatonigral projections. Interestingly, in the tight unmyelinated axon bundle of the olfactory nerve, the 'ephaptic' interaction can lead to synchronized firing of independently stimulated axons ${ }^{48}$. In this regard, although we could not observe loosening of axon fasciculation in $S c n 4 b$-null mice, the depletion of $\beta 4$ would be inconvenient for electrical interaction through the invisible extracellular space ${ }^{49}$. In any case, reduction of the number and frequency of spikes during the Up-state might somehow cause involuntary movements such as tremor-like movement observed in Scn4b-null mice and choreic movement in HD, which shows reduced $\beta 4$ expression.

In contrast, we found a slow conduction velocity of MSN axons of WT mice, which is compatible with a previous report ${ }^{50}$ and with the fact that those axons are unmyelinated. The conduction velocity of MSN axons in Scn4b-null mice was not significantly different from that of WT mice, indicating that the densities of VGSCs along MSN axons and their diameters might be unaffected by deletion of $\beta 4$. This was confirmed by examining the distribution of Nav1.2 in Scn $4 b^{-/-(m c)}$-Venus mouse. Nav1.2 is localized throughout the Venus-positive striatal projection fibres in WT-Venus mouse, and the similar distribution of Nav1.2 immunoreactivity was observed in $S c n 4 b^{-/-(m c)}$-Venus mouse (Supplementary Fig. 8). This result suggests that Nav1.2 localization was not affected by $\beta 4$ ablation.

VGSCs are key molecules of epilepsy and cardiac death ${ }^{51,52}$. $\beta 4$ is expressed in both the brain and heart, and interacts with Nav1.5, which is the major $\alpha$-subunit in heart cells ${ }^{53}$. It has been reported that $S C N 4 B$ mutations are associated with cardiac death $^{53,54}$, whereas SCN $4 B$ mutations related to epilepsy have not been identified. We observed sudden unexpected death in $S c n 4 b$ null mice without seizure, suggesting that $\beta 4$ ablation might be related to a cardiac abnormality rather than epilepsy.

In summary, we found atypical localization of $\beta 4$ in the striatum, leading us to identify striatal projection fibres forming large unmyelinated inhibitory fibre bundles and to confirm that $\beta 4$ functions as a physiological channel modulator in striatal MSNs.

\section{Methods}

Antibodies. Antibodies were listed in Supplementary Table 1.

Generation of anti-SCN4B antibodies. Rat monoclonal anti-hSCN4B-C (7D7F10) antibody was generated against KLH-conjugated oligopeptides corresponding to the C-terminal region of human $\beta 4$ (amino acids 209-228). Hybridoma supernatants were screened by ELISA, and then selected subclones were further analysed by western blot and immunohistochemistry. Conditioned media of a selected clone (7D7F10) were harvested from the stable hybridoma cultures, and antibody was purified using a HiTrap SP HP column (GE Healthcare) by Cell Engineering Corporation (Osaka, Japan). Rabbit polyclonal anti-mSCN4B-EC 
antibody was generated against recombinant protein corresponding to the extracellular region of mouse $\beta 4$ (amino acid 30-160).

Animals. We generated three genetically modified mice. One is $S c n 4 b$-Venus transgenic mouse, which expresses the fluorescent marker Venus under the control of the 9-kb $S c n 4 b$ promoter (Fig. 3a) (Details are described in Supplementary Methods) and others are Scn $4 b$-deficient mice with or without mCherry-V5-His and neomycin-resistant gene cassettes (Fig. 6a), which are described as $S c n 4 b^{-/-(m c)}$ and $S c n 4 b^{-/-}$mice, respectively (Details are described in Supplementary Methods). To visualize striatonigral projection fibres of the $S c n 4 b$ deficient mice, $S c n 4 b^{(m c)}$ mutant mouse was crossed with $S c n 4 b$-Venus transgenic mouse.

All experiments were carried out in accordance with the guidelines for Animal Care of the Riken Brain Science Institute. Both male and female mice were used for this study.

Tissue preparation. For in situ hybridization (ISH) and immunohistochemistry (IHC), mice were perfused with PBS followed by $4 \%$ paraformaldehyde (PFA) in PBS. To prepare frozen sections, brains were postfixed by $4 \%$ PFA in PBS overnight, immersed in $30 \%$ sucrose (wt/vol) in PBS, embedded in OCT compound, immediately frozen by solid $\mathrm{CO}_{2}$ and stored at $-80^{\circ} \mathrm{C}$. We cut $20-\mu \mathrm{m}$-thick sections with an HM 560 CryoStar Cryostat (Thermo Scientific) and 100- $\mu$ m-thick sections were cut with a ROM380-CN sliding microtome (Yamato Kohki). To prepare paraffin sections, brains were postfixed, dehydrated and embedded in paraffin wax. Five- $\mu$ m-thick sections were cut with an HM430 sliding microtome (Leica).

ISH. A cDNA fragment encoding $S c n 4 b$ was obtained from IMAGE clone (IMAGE 1282676). cDNA fragments encoding $S c n 1 b, S c n 2 b$ and $S c n 3 b$ were amplified using KOD-plus polymerase (Toyobo) with specific primers anchored with appropriate restriction enzyme recognition sites $(S c n 1 b, S c n 2 b)$ or SP6 promoter sequence $(S c n 3 b)$. Amplified Scn $1 b$ and $S c n 2 b$ cDNA were subcloned into pcDNA3.1/V5-His $\mathrm{C}$ vector (Invitrogen) and the sequences were confirmed by DNA sequencing. NotIdigested $S c n 1 b, S c n 2 b$ and $S c n 4 b$, as well as amplified $S c n 3 b$, were used as templates to synthesize Digoxigenin-labelled cRNA probes. Those probes were prepared by MEGAscript T3 (Scn4b), T7 (Scn1b and Scn2b) or SP6 (Scn3b) Kit (Invitrogen) and DIG RNA Labelling Mix (Roche) according to the manufacturer's instructions. Sections were incubated with PBS for $10 \mathrm{~min}$, postfixed with $4 \%$ formalin/PBS for $5 \mathrm{~min}$, acetylated with $0.25 \%$ acetic anhydride/ $0.1 \mathrm{M}$ triethanolamine ( $\mathrm{pH} 8.0$ ) for $10 \mathrm{~min}$ and washed with PBS. The sections were incubated in a prehybridization solution ( $50 \%$ formamide, $5 \times$ SSPE, $0.1 \%$ SDS, $1 \mathrm{mg}$ Yeast tRNA (Roche)) for $2 \mathrm{~h}$ at $60^{\circ} \mathrm{C}$, and then hybridized with digoxigenin-labelled cRNA probe $\left(1 \mathrm{ng} \mathrm{\mu l}^{-1} \mathrm{cRNA}\right.$ probe containing prehybridization solution) overnight at $60^{\circ} \mathrm{C}$. Next, sections were washed with $2 \times \mathrm{SSC} / 50 \%$ formamide for $15 \mathrm{~min}$ at $50{ }^{\circ} \mathrm{C}$ two times and sequentially treated with RNase buffer $\left(20 \mu \mathrm{g} \mathrm{ml}^{-1}\right.$ RNase A (Sigma) containing $10 \mathrm{mM}$ Tris$\mathrm{HCl}, \mathrm{pH} 8.0,10 \mathrm{mM}$ EDTA, $0.5 \mathrm{M} \mathrm{NaCl}$ ) for $15 \mathrm{~min}$ at $37^{\circ} \mathrm{C} ; 2 \times \mathrm{SSC}$ for $15 \mathrm{~min}$ at $37^{\circ} \mathrm{C}$, two times; $0.2 \times$ SSC for $15 \mathrm{~min}$ at $37^{\circ} \mathrm{C}$, two times. The sections were replaced in TBS and incubated with Blocking Regent (Roche) for $1 \mathrm{~h}$, followed by alkaline phosphatase-conjugated anti-digoxigenin antibody, which was diluted with Solution B of Can Get Signal Immunostain (Toyobo) to enhance the signal, for $1 \mathrm{~h}$. The sections were washed with TBST $(0.05 \%$ TritonX-100) for $10 \mathrm{~min}$, two times, and then treated with NTMT (0.1 M Tris- $\mathrm{HCl}(\mathrm{pH} 9.5) / 0.1 \mathrm{M} \mathrm{NaCl} / 0.05 \mathrm{M} \mathrm{MgCl}_{2} /$ $0.1 \%$ Tween 20 ) for $10 \mathrm{~min}$. To visualize the signal, sections were developed with BCIP/NBT (Roche) diluted with NTMT/10\% polyvinyl alcohol according to the manufacturer's instruction for $2-3$ days at $4{ }^{\circ} \mathrm{C}$

IHC. Autoclaved paraffin sections and 20 - $\mu \mathrm{m}$-thick frozen sections were incubated with blocking solution containing 5\% skim milk in TBST, for $1 \mathrm{~h}$. The sections were incubated with primary antibodies in TBST for overnight at $4{ }^{\circ} \mathrm{C}$, followed by secondary antibodies. For diaminobenzidine (DAB) staining, sections were quenched $3 \% \mathrm{H}_{2} \mathrm{O}_{2} /$ methanol for 30 min before blocking, and incubated with VECTASTAIN Elite ABC Kit (Vector Laboratories) for 30 min after secondary antibody incubation. Then they were developed with substrate solution $(0.1 \% \mathrm{DAB} / 0.015 \%$ peroxidase/0.05 M Tris-HCl (pH7.6)). Hundred- $\mu$ m-thick frozen sections were stained by the following floating method. The sections were permeabilized with $0.2 \%$ TritonX-100 and incubated with blocking solution containing $2 \%$ BSA in TBST. The sections were transferred to primary antibody solution containing $2 \%$ BSA in TBST overnight at $4{ }^{\circ} \mathrm{C}$, incubated with fluorescent secondary antibody solution containing $2 \%$ BSA in TBST for $3 \mathrm{~h}$ and then mounted with VECTASHIELD Mounting Medium (Vector Laboratories). Images were taken with a BIOREVO BZ-9000 (KEYENCE), TCS SP2 and SP5 confocal microscope (Leica), and we captured approximately the same area in each comparative sample.

Combined staining of ISH (Scn4b) and IHC (anti-GFP). Procedures were combined for ISH and IHC with modification. Sections were pretreated and sequentially incubated with cRNA probe, RNase buffer, blocking regent and antidigoxigenin antibody as ISH. To detect Venus immunoreactivity, sections were stained by anti-GFP (Roche), followed by Alexa Fluor 488 anti-mouse IgG.
Fluorescent alkaline phosphatase activity was detected using HNPP Fluorescent Detection Set (Roche) according to the manufacturer's instructions, and the sections were mounted with CC/Mount (Diagnostic BioSystems).

Western blot. Mouse brains or their subregions were rapidly isolated and homogenized with lysis buffer (20 mM Tris- $\mathrm{HCl}$ ( $\mathrm{pH} 7.4), 150 \mathrm{mM} \mathrm{NaCl}$, Complete Protease Inhibitor Cocktail Tablet, EDTA-free (Roche)). To remove debris and the nuclei fraction from the brain homogenates, they were centrifuged at 1,000 r.p.m. for $10 \mathrm{~min}$ at $4^{\circ} \mathrm{C}$. The supernatants were considered 'brain lysate' To purify the membrane fraction from the lysates, they were centrifuged at 40,000 r.p.m. for $20 \mathrm{~min}$ at $4{ }^{\circ} \mathrm{C}$ sequentially. Concentration of the protein samples was quantified by BCA assay (Thermo Fisher Scientific) followed by boiling with SDS sample buffer at $100{ }^{\circ} \mathrm{C}$ for $3 \mathrm{~min}$. Protein samples were loaded onto 5-20\% SDS-PAGE gels (ATTO), transferred onto PVDF membranes (Millipore) and incubated with primary antibodies overnight at $4{ }^{\circ} \mathrm{C}$. After incubation with secondary antibodies, all blots were developed using Luminata Forte Western HRP substrate (Millipore). Images were taken by ImageQuant LAS 4000 (GE Healthcare) and band intensities on blots were quantified by NIH ImageJ. Full-size images of western blots are shown in Supplementary Fig. 10

Tremor test. A tremor test was carried out in 12 -week-old male $S c n 4 b$ mutant mice of each genotype. A mouse was placed in a semitransparent plastic box glued with an accelerometer (MVP-RF8-HC, MicroStone) at the bottom and moved freely. The box was suspended with thread. The motion of the mouse was recorded automatically for $1-5 \mathrm{~min}$ at a sampling rate of $1 \mathrm{kHz}$. Motion power percentage $(\mathrm{MPP})^{55}$ was calculated as (sum of amplitude at $20.5-40 \mathrm{~Hz}$ )/(sum of amplitude at $0-80 \mathrm{~Hz}) \times 100$ for each $1.024 \mathrm{~s}$ and averaged for every minute.

Slice preparation and acute isolation of neurons. The brain was removed from mice at P17-18, chilled, sliced (500- $\mu \mathrm{m}$ thick) coronally in ice-cold artificial cerebrospinal fluid (ACSF) containing the following components (in mM): $124 \mathrm{NaCl}$ $3 \mathrm{KCl}, 1 \mathrm{NaH}_{2} \mathrm{PO}_{4}, 1.2 \mathrm{MgCl}_{2}, 2.4 \mathrm{CaCl}_{2}, 10$ glucose, buffered to $\mathrm{pH} 7.4$ with $\mathrm{NaHCO}_{3}(26 \mathrm{mM})$, and saturated with $95 \% \mathrm{O}_{2}$ and $5 \% \mathrm{CO}_{2}$ where it was held for $1 \mathrm{~h}$ at room temperature. The slices were then placed in ACSF warmed to $31^{\circ} \mathrm{C}$, saturated with $95 \% \mathrm{O}_{2}$ and $5 \% \mathrm{CO}_{2}$ and containing pronase $\left(0.17 \mathrm{mg} \mathrm{ml}^{-1}\right)$ for $110 \mathrm{~min}$. Enzyme digestion was terminated by transferring the slices to HEPESbuffered saline (HBS) maintained at $26^{\circ} \mathrm{C}$ and containing the following (in mM): $150 \mathrm{NaCl}, 5 \mathrm{KCl}, 1 \mathrm{MgCl}_{2}, 10$ glucose, 1 HEPES and $2 \mathrm{CaCl}_{2}$, buffered to $\mathrm{pH} 7.4$ with Tris- $\mathrm{HCl}(5 \mathrm{mM})$. The striatum was dissected from the slices and triturated for mechanical dissociation of neurons of the striatum and then placed in a recording chamber coated with poly-L-lysine for $15 \mathrm{~min}^{56}$. Phase-bright mediumsized neurons with a few sufficiently long neurites were chosen as MSNs in the striatum.

Whole-cell voltage-clamp recordings in isolated neurons. Whole-cell voltageclamp recordings of $\mathrm{Na}^{+}$currents were performed in HBS at room temperature with an EPC9/2 amplifier and PULSE software (HEKA Elektronik, Lambrecht/ Pfalz;; $5 \mathrm{kHz}$ filtering, $50 \mathrm{kHz}$ sampling), with infrared differential contrast visualization using a BX50WI microscope (Olympus, Dage-MTI). The internal solution contained the following (in $\mathrm{mM}$ ): $110 \mathrm{CsCH}_{3} \mathrm{SO}_{3}, 11 \mathrm{CsCl}, 2 \mathrm{MgCl}_{2}, 10$ tetraethylammonium (TEA)-Cl, 10 HEPES, $4 \mathrm{Na}_{2} \mathrm{ATP}, 0.3 \mathrm{NaGTP}, 0.1$ EGTA ( $\mathrm{pH} 7.4$ with $\mathrm{CsOH}$ ). The external solutions used for recordings consisted of HBS containing (in mM) 10 TEA-Cl and $0.2 \mathrm{CdCl}_{2}$ with or without tetrodotoxin (TTX, $1 \mu \mathrm{M}$ ). Recordings were made first in $\mathrm{HBS}$ with TEA-Cl and $\mathrm{CdCl}_{2}$, and repeated in the same solutions but including TTX. TTX-sensitive $\mathrm{Na}^{+}$current was obtained by subtraction. Electrodes were pulled and fire-polished to yield resistance of 4-6 M $\Omega$ in the bath. For voltage-clamp recording, series resistance $\left(8 \sim 35 \mathrm{M} \Omega\right.$; WT $\left.14.8 \pm 1.8, n=17 ; \operatorname{Scn} 4 b^{-9-(m c)} 14.5 \pm 1.3, n=19\right)$ was compensated online by $50-70 \%$. Liquid junction potential $(\sim 10 \mathrm{mV})$ was adjusted offline. Leak current subtraction was performed by a $\mathrm{P} / 4$ procedure.

Whole-cell current-clamp recordings in slice preparation. Coronal brain slices (250- $\mu \mathrm{m}$ thick) were obtained from mice at P30-58 as stated above and transferred to a recording chamber, which was continuously perfused with ACSF at a rate of $1-2 \mathrm{ml} \mathrm{min}^{-1}$ at $30^{\circ} \mathrm{C}$. Whole-cell current-clamp recordings $(5 \mathrm{kHz}$ filtering, $20 \mathrm{kHz}$ sampling) were collected using patch pipettes $(4 \sim 6 \mathrm{M} \Omega)$ containing the following (in $\mathrm{mM}$ ): $129 \mathrm{~K}$-gluconate, $11 \mathrm{KCl}, 2 \mathrm{MgCl}_{2}, 10 \mathrm{HEPES}, 4 \mathrm{Na}_{2}$-ATP, 0.3 GTP and $0.5 \%$ biocytin (brought to $\mathrm{pH} 7.3$ with $\mathrm{KOH}$; osmolality, $280 \mathrm{mOsm}$ ). For current-clamp recording, series resistance $(5 \sim 20 \mathrm{M} \Omega$, WT $10.9 \pm 0.7, n=34$, Scn $\left.4 b^{-/-(m c)} 11.6 \pm 0.6, n=32\right)$ was compensated online by $50-70 \%$. Membrane potentials were not corrected for liquid junction potentials $(\sim 13 \mathrm{mV})$.

Electron microscopy and pre-embedding immuno-EM. For EM, mice were perfused with $2 \%$ PFA, $2.5 \%$ glutaraldehyde in $0.05 \mathrm{M}$ sodium cacodylate ( $\mathrm{pH} 7.4$ ). Slices of striatum and substantia nigra were removed and postfixed overnight. Slices were fixed in $1 \% \mathrm{OsO} 4$ in $0.05 \mathrm{M}$ sodium cacodylate ( $\mathrm{pH} 7.4$ ) for $1 \mathrm{~h}$, dehydrated in a graded series of ethanol and embedded in epoxy resin. Ultrathin 
$(100 \mathrm{~nm})$ coronal sections were prepared by ultramicrotome Leica EM UC6 (Leica) and stained $1 \%$ uranyl acetate solution for $15 \mathrm{~min}$ at $50{ }^{\circ} \mathrm{C}$, followed by Lead stain solution (Sigma) for $10 \mathrm{~min}$ at room temperature. Stained sections were analysed with JEOL1200EX II (JEOL). For immune-EM, mice were perfused with $2 \%$ PFA, $0.5 \%$ glutaraldehyde in $0.05 \mathrm{M}$ sodium cacodylate $(\mathrm{pH} 7.4)$. Coronal slices of striatum (200 $\mu$ m-thick) were cut with a VT1000S vibrating blade microtome (Leica) and immersed 30\% sucrose (wt/vol) in TBS. The slices were frozen with liquid nitrogen and thawed with TBS three times. The slices were incubated with TBS containing $0.1 \% \mathrm{H}_{2} \mathrm{O}_{2}$ for $1 \mathrm{~h}$, followed by blocking solution ( $2 \% \mathrm{BSA}$ in TBS) for $2 \mathrm{~h}$. The slices were transferred to primary antibody solution (anti-mSCN4B-C, $1: 3,000)$ containing $2 \%$ BSA in TBS overnight at $4{ }^{\circ} \mathrm{C}$, incubated with biotinylated secondary antibody solution (1:500) containing $2 \%$ BSA in TBS for $3 \mathrm{~h}$, and then incubated with VECTASTAIN Elite ABC Kit (Vector Laboratories) for $2 \mathrm{~h}$, followed by DAB substrate solution $(5 \mathrm{mg} \mathrm{DAB} / 40 \mathrm{ml} 0.05 \mathrm{M}$ Tris- $\mathrm{HCl}(\mathrm{pH} 7.4) / 3 \mathrm{ul}$ $0.3 \% \mathrm{H}_{2} \mathrm{O}_{2}$ ) for $20 \mathrm{~min}$. The slices were fixed in $1 \% \mathrm{OsO} 4$ solution, dehydrated in a graded series of ethanol and embedded in epoxy resin. Ultrathin (100-nm thick) coronal sections were stained using $1 \%$ uranyl acetate solution for $5 \mathrm{~min}$ at $50^{\circ} \mathrm{C}$, followed by Lead stain solution (Sigma) for $10 \mathrm{~min}$ at room temperature. Stained sections were analysed with JEOL1200EX II (JEOL).

Statictics. Sample sizes were determined on the basis of pilot experiments and previous experience from similar experiments. To examine whether the samples had the same variances, we first analysed them by F-test. We excluded an outlier sample calculated by Grubb's test in Fig. 7b,c. All of the experiments were successfully repeated at least two times. Data are presented as means \pm s.e.m. and were analysed with the unpaired Student's $t$-test, unpaired $t$-test with Welch's correction or one-way ANOVA followed by Tukey's post hoc test. ${ }^{\star} P<0.05,{ }^{*} P<0.01$, and ${ }_{* * *} P<0.001$. A $P$-value of $<0.05$ was considered statistically significant.

\section{References}

1. Lai, H. C. \& Jan, L. Y. The distribution and targeting of neuronal voltage-gated ion channels. Nat. Rev. Neurosci. 7, 548-562 (2006).

2. Brackenbury, W. J. \& Isom, L. L. Na channel beta subunits: overachievers of the ion channel family. Front Pharmacol. 2, 53 (2011).

3. Chen, C. et al. Reduced sodium channel density, altered voltage dependence of inactivation, and increased susceptibility to seizures in mice lacking sodium channel beta 2-subunits. Proc. Natl Acad. Sci. USA 99, 17072-17077 (2002).

4. Brackenbury, W. J. et al. Functional reciprocity between $\mathrm{Na}+$ channel Navl.6 and betal subunits in the coordinated regulation of excitability and neurite outgrowth. Proc. Natl Acad. Sci. USA 107, 2283-2288 (2010).

5. Brackenbury, W. J. et al. Voltage-gated $\mathrm{Na}+$ channel betal subunit-mediated neurite outgrowth requires Fyn kinase and contributes to postnatal CNS development in vivo. J. Neurosci. 28, 3246-3256 (2008).

6. Isom, L. L. et al. Structure and function of the beta 2 subunit of brain sodium channels, a transmembrane glycoprotein with a CAM motif. Cell 83, 433-442 (1995).

7. Yu, F. H. et al. Sodium channel beta4, a new disulfide-linked auxiliary subunit with similarity to beta2. J. Neurosci. 23, 7577-7585 (2003)

8. Buffington, S. A. \& Rasband, M. N. Na + channel-dependent recruitment of Navbeta4 to axon initial segments and nodes of Ranvier. J. Neurosci. 33, 6191-6202 (2013).

9. Bant, J. S. \& Raman, I. M. Control of transient, resurgent, and persistent current by open-channel block by Na channel beta 4 in cultured cerebellar granule neurons. Proc. Natl Acad. Sci. USA 107, 12357-12362 (2010).

10. Grieco, T. M., Malhotra, J. D., Chen, C., Isom, L. L. \& Raman, I. M. Openchannel block by the cytoplasmic tail of sodium channel beta4 as a mechanism for resurgent sodium current. Neuron 45, 233-244 (2005).

11. Raman, I. M. \& Bean, B. P. Resurgent sodium current and action potential formation in dissociated cerebellar Purkinje neurons. J. Neurosci. 17, 4517-4526 (1997).

12. Oyama, F. et al. Sodium channel beta4 subunit: down-regulation and possible involvement in neuritic degeneration in Huntington's disease transgenic mice. J. Neurochem. 98, 518-529 (2006).

13. Miyazaki, H. et al. BACE1 modulates filopodia-like protrusions induced by sodium channel beta4 subunit. Biochem. Biophys. Res. Commun. 361, 43-48 (2007).

14. Wong, H. K. et al. beta Subunits of voltage-gated sodium channels are novel substrates of beta-site amyloid precursor protein-cleaving enzyme (BACE1) and gamma-secretase. J. Biol. Chem. 280, 23009-23017 (2005).

15. Sheng, M., Tsaur, M. L., Jan, Y. N. \& Jan, L. Y. Contrasting subcellular localization of the Kv1.2 $\mathrm{K}+$ channel subunit in different neurons of rat brain. J. Neurosci. 14, 2408-2417 (1994).

16. Perrot, R., Berges, R., Bocquet, A. \& Eyer, J. Review of the multiple aspects of neurofilament functions, and their possible contribution to neurodegeneration. Mol. Neurobiol. 38, 27-65 (2008).

17. Yuan, A., Rao, M. V., Veeranna \& Nixon, R. A. Neurofilaments at a glance. J. Cell Sci. 125, 3257-3263 (2012).
18. Nagai, T. et al. A variant of yellow fluorescent protein with fast and efficient maturation for cell-biological applications. Nat. Biotechnol. 20, 87-90 (2002).

19. Durieux, P. F., Schiffmann, S. N. \& de Kerchove d'Exaerde, A. Targeting neuronal populations of the striatum. Front Neuroanat. 5, 40 (2011).

20. Koshimizu, Y. et al. Paucity of enkephalin production in neostriatal striosomal neurons: analysis with preproenkephalin-green fluorescent protein transgenic mice. Eur. J. Neurosci. 28, 2053-2064 (2008).

21. Ogiwara, I. et al. Nav1.1 localizes to axons of parvalbumin-positive inhibitory interneurons: a circuit basis for epileptic seizures in mice carrying an Scnla gene mutation. J. Neurosci. 27, 5903-5914 (2007).

22. Westenbroek, R. E., Merrick, D. K. \& Catterall, W. A. Differential subcellular localization of the RI and RII $\mathrm{Na}+$ channel subtypes in central neurons. Neuron 3, 695-704 (1989).

23. Boiko, T. et al. Compact myelin dictates the differential targeting of two sodium channel isoforms in the same axon. Neuron 30, 91-104 (2001).

24. Malhotra, J. D., Kazen-Gillespie, K., Hortsch, M. \& Isom, L. L. Sodium channel beta subunits mediate homophilic cell adhesion and recruit ankyrin to points of cell-cell contact. J. Biol. Chem. 275, 11383-11388 (2000).

25. Huang, Q. et al. Immunohistochemical localization of the D1 dopamine receptor in rat brain reveals its axonal transport, pre- and postsynaptic localization, and prevalence in the basal ganglia, limbic system, and thalamic reticular nucleus. Proc. Natl Acad. Sci. USA 89, 11988-11992 (1992).

26. Yung, K. K. et al. Immunocytochemical localization of D1 and D2 dopamine receptors in the basal ganglia of the rat: light and electron microscopy. Neuroscience 65, 709-730 (1995).

27. Caille, I., Dumartin, B. \& Bloch, B. Ultrastructural localization of D1 dopamine receptor immunoreactivity in rat striatonigral neurons and its relation with dopaminergic innervation. Brain Res. 730, 17-31 (1996).

28. Sesack, S. R., Aoki, C. \& Pickel, V. M. Ultrastructural localization of D2 receptor-like immunoreactivity in midbrain dopamine neurons and their striatal targets. J. Neurosci. 14, 88-106 (1994).

29. Mengual, E. \& Pickel, V. M. Ultrastructural immunocytochemical localization of the dopamine D2 receptor and tyrosine hydroxylase in the rat ventral pallidum. Synapse 43, 151-162 (2002).

30. Wang, S. S. et al. Functional trade-offs in white matter axonal scaling. J. Neurosci. 28, 4047-4056 (2008).

31. Pissadaki, E. K. \& Bolam, J. P. The energy cost of action potential propagation in dopamine neurons: clues to susceptibility in Parkinson's disease. Front Comput. Neurosci. 7, 13 (2013).

32. Bonfanti, L. \& Peretto, P. Adult neurogenesis in mammals-a theme with many variations. Eur. J. Neurosci. 34, 930-950 (2011).

33. Ziskin, J. L., Nishiyama, A., Rubio, M., Fukaya, M. \& Bergles, D. E. Vesicular release of glutamate from unmyelinated axons in white matter. Nat. Neurosci. 10, 321-330 (2007)

34. Kukley, M., Capetillo-Zarate, E. \& Dietrich, D. Vesicular glutamate release from axons in white matter. Nat. Neurosci. 10, 311-320 (2007).

35. Brackenbury, W. J., Yuan, Y., O’Malley, H. A., Parent, J. M. \& Isom, L. L. Abnormal neuronal patterning occurs during early postnatal brain development of Scn1b-null mice and precedes hyperexcitability. Proc. Natl Acad. Sci. USA 110, 1089-1094 (2013).

36. Sutkowski, E. M. \& Catterall, W. A. Beta 1 subunits of sodium channels. Studies with subunit-specific antibodies. J. Biolo. Chem. 265, 12393-12399 (1990).

37. Sakurai, T. et al. Overlapping functions of the cell adhesion molecules Nr-CAM and L1 in cerebellar granule cell development. J. Cell Biol. 154, 1259-1273 (2001).

38. Crill, W. E. Persistent sodium current in mammalian central neurons. Annu. Rev. Physiol. 58, 349-362 (1996).

39. Cruz, J. S. et al. Resurgent $\mathrm{Na}+$ current: a new avenue to neuronal excitability control. Life Sci. 89, 564-569 (2011).

40. Goldfarb, M. Voltage-gated sodium channel-associated proteins and alternative mechanisms of inactivation and block. Cell Mol. Life. Sci. 69, 1067-1076 (2012).

41. Cannon, S. C. \& Bean, B. P. Sodium channels gone wild: resurgent current from neuronal and muscle channelopathies. J. Clin. Invest. 120, 80-83 (2010).

42. Bean, B. P. The molecular machinery of resurgent sodium current revealed Neuron 45, 185-187 (2005).

43. Khaliq, Z. M., Gouwens, N. W. \& Raman, I. M. The contribution of resurgent sodium current to high-frequency firing in Purkinje neurons: an experimental and modeling study. J. Neurosci. 23, 4899-4912 (2003).

44. Wilson, C. J. \& Kawaguchi, Y. The origins of two-state spontaneous membrane potential fluctuations of neostriatal spiny neurons. J. Neurosci. 16, 2397-2410 (1996).

45. Kim, J. H., Kushmerick, C. \& von Gersdorff, H. Presynaptic resurgent Na + currents sculpt the action potential waveform and increase firing reliability at a CNS nerve terminal. J. Neurosci. 30, 15479-15490 (2010).

46. Yang, Z. \& Wang, J. H. Frequency-dependent reliability of spike propagation is function of axonal voltage-gated sodium channels in cerebellar Purkinje cells. Cerebellum. 12, 862-869 (2013). 
47. Klinger, A. B. et al. Sea-anemone toxin ATX-II elicits A-fiber-dependent pain and enhances resurgent and persistent sodium currents in large sensory neurons. Mol. Pain. 8, 69 (2012).

48. Bokil, H., Laaris, N., Blinder, K., Ennis, M. \& Keller, A. Ephaptic interactions in the mammalian olfactory system. J. Neurosci. 21, RC173 (2001).

49. Debanne, D., Campanac, E., Bialowas, A., Carlier, E. \& Alcaraz, G. Axon physiology. Physiol. Rev. 91, 555-602 (2011).

50. Nambu, A. \& Llinas, R. Electrophysiology of globus pallidus neurons in vitro. J. Neurophysiol. 72, 1127-1139 (1994).

51. Oliva, M., Berkovic, S. F. \& Petrou, S. Sodium channels and the neurobiology of epilepsy. Epilepsia 53, 1849-1859 (2012).

52. Wilde, A. A. \& Brugada, R. Phenotypical manifestations of mutations in the genes encoding subunits of the cardiac sodium channel. Circ. Res. 108, 884-897 (2011).

53. Medeiros-Domingo, A. et al. SCN4B-encoded sodium channel beta4 subunit in congenital long-QT syndrome. Circulation 116, 134-142 (2007).

54. Tan, B. H. et al. Sudden infant death syndrome-associated mutations in the sodium channel beta subunits. Heart Rhythm. 7, 771-778 (2010).

55. Martin, F. C., Thu Le, A. \& Handforth, A. Harmaline-induced tremor as a potential preclinical screening method for essential tremor medications. Mov. Disord. 20, 298-305 (2005).

56. Yamada, K. et al. Protective role of ATP-sensitive potassium channels in hypoxia-induced generalized seizure. Science 292, 1543-1546 (2001).

\section{Acknowledgements}

We thank Dr Mika Tanaka (RIKEN BSI) for supporting the generation of Scn $4 b$-Venus transgenic mice. We thank Takumi Akagi (RIKEN BSI) for technical support and advice on EM analysis. We thank Dr Toshihiko Hosoya (RIKEN BSI) for teaching the technique of fluorescence in situ hybridization. We thank Dr Jun-ichi Miyazaki (Osaka University) for providing the $C A G$-Cre deleter mouse and Dr Shigeyoshi Itohara (RIKEN BSI) for providing the $C A G-C r e$ and $C A G-F L P e$ deleter mouse. This work was supported by a
Grant-in-Aid from the Ministry of Education, Culture, Sports, Science and Technology (MEXT) of Japan to N.N. (22110004 for Scientific Research on Innovated Areas 'Foundation of Synapse and Neurocircuit Pathology', 22240037, 24659436, 25253066), by CREST from JST to N.N. and by a Grant-in-Aid for the Research on Measures for Ataxic Diseases from the Ministry of Health, Welfare and Labor to N.N.

\section{Author contributions}

H.M., T.S., N.H. and N.N. conceived the project. H.M., F.O., R.I., T.A. and M.M. designed the experiments. H.M. carried out immunohistochemical analysis (Figs 1-5,7 and Supplementary Figs 1,3-6,8), in situ hybridization (Figs 2,6 and Supplementary Fig. 4) and western blot analysis (Figs 6,7 and Supplementary Figs 4,7,10). H.M. and J.S carried out EM and immunoEM analysis (Figs 4,7 and Supplementary Fig. 2). R.I., T.A., K.N., K.Y. and M.M. carried out electrophysiological analysis (Figs 8,9 and Table 1). F.O., Y.K. and M.K. generated Scn $4 b$-Venus transgenic mice and F.O., T.A. and H.K. generated $S c n 4 b$-null mice. Y.K., F.F. and T.K. provided PPE-GFP transgenic mice. H.M. and Y.K. performed tremor analysis (Supplementary Fig. 4). I.O. and K.Y. provided an Nav1.6 antibody. H.M., F.O. and H.S. produced anti- $\beta$ subunit antibodies. H.M. and N.N. wrote the manuscript.

\section{Additional information}

Supplementary Information accompanies this paper at http://www.nature.com/ naturecommunications

Competing financial interests: The authors declare no competing financial interests.

Reprints and permission information is available online at http://npg.nature.com/ reprintsandpermissions/

How to cite this article: Miyazaki, H. et al. Singular localization of sodium channel $\beta 4$ subunit in unmyelinated fibres and its role in striatum. Nat. Commun. 5:5525 doi: 10.1038/ncomms6525 (2014). 